Review

\title{
Survey of MRI Usefulness for the Clinical Assessment of Bone Microstructure
}

\author{
Enrico Soldati ${ }^{1,2,3, * \mathbb{D}}$, Francesca Rossi ${ }^{4}$, Jerome Vicente ${ }^{2}$, Daphne Guenoun ${ }^{3,5}$, Martine Pithioux ${ }^{3,6} \mathbb{D}$, \\ Stefano Iotti ${ }^{4,7}$, Emil Malucelli ${ }^{4}$ (D) and David Bendahan ${ }^{1}$
}

1 CRMBM, CNRS, Aix Marseille University, 13385 Marseille, France; david.bendahan@univ-amu.fr

2 IUSTI, CNRS, Aix Marseille University, 13013 Marseille, France; jerome.vicente@univ-amu.fr

3 ISM, CNRS, Aix Marseille University, 13288 Marseille, France; daphne.guenoun@ap-hm.fr (D.G.); martine.pithioux@univ-amu.fr (M.P.)

4 Department of Pharmacy and Biotechnology, University of Bologna, 40126 Bologna, Italy; francesca.rossi105@unibo.it (F.R.); stefano.iotti@unibo.it (S.I.); emil.malucelli@unibo.it (E.M.)

5 Department of Radiology, Institute for Locomotion, Saint-Marguerite Hospital, ISM, CNRS, APHM, Aix Marseille University, 13274 Marseille, France

6 Department of Orthopedics and Traumatology, Institute for Locomotion, Saint-Marguerite Hospital, ISM, CNRS, APHM, Aix Marseille University, 13274 Marseille, France

7 National Institute of Biostructures and Biosystems, 00136 Rome, Italy

* Correspondence: enrico.soldati@univ-amu.fr

Citation: Soldati, E.; Rossi, F.; Vicente, J.; Guenoun, D.; Pithioux, M.; Iotti, S.; Malucelli, E.; Bendahan, D. Survey of MRI Usefulness for the Clinical Assessment of Bone Microstructure. Int. J. Mol. Sci. 2021, 22, 2509. https://doi.org/ 10.3390/ijms22052509

Academic Editor: Sun-Woong Kang

Received: 30 January 2021

Accepted: 25 February 2021

Published: 2 March 2021

Publisher's Note: MDPI stays neutral with regard to jurisdictional claims in published maps and institutional affiliations.

Copyright: (c) 2021 by the authors. Licensee MDPI, Basel, Switzerland. This article is an open access article distributed under the terms and conditions of the Creative Commons Attribution (CC BY) license (https:// creativecommons.org/licenses/by/ $4.0 /)$.

\begin{abstract}
Bone microarchitecture has been shown to provide useful information regarding the evaluation of skeleton quality with an added value to areal bone mineral density, which can be used for the diagnosis of several bone diseases. Bone mineral density estimated from dual-energy X-ray absorptiometry (DXA) has shown to be a limited tool to identify patients' risk stratification and therapy delivery. Magnetic resonance imaging (MRI) has been proposed as another technique to assess bone quality and fracture risk by evaluating the bone structure and microarchitecture. To date, MRI is the only completely non-invasive and non-ionizing imaging modality that can assess both cortical and trabecular bone in vivo. In this review article, we reported a survey regarding the clinically relevant information MRI could provide for the assessment of the inner trabecular morphology of different bone segments. The last section will be devoted to the upcoming MRI applications (MR spectroscopy and chemical shift encoding MRI, solid state MRI and quantitative susceptibility mapping), which could provide additional biomarkers for the assessment of bone microarchitecture.
\end{abstract}

Keywords: MRI; bone microarchitecture; bone morphology; bone quality

\section{Introduction \\ 1.1. Bone Disorders and Investigative Tools}

A large number of studies have demonstrated the substantial burden of bone disorders worldwide [1-3]. Considered as the second greatest cause of disability [1], musculoskeletal pathologies account for $6.8 \%$ of total disability worldwide [2]. Bone pathologies are usually affecting the bones solid phase, which is composed of both cortical and cancellous/trabecular types of bone. Bone alterations commonly include cortical shell thinning, increased porosity of both cortical and trabecular bone phases [4,5], and reduced density, volume, and regenerative power. These bone modifications generally account for a reduced resistivity and flexibility eventually leading to an increased risk of fragility fractures accompanied by long-term disabilities. Recent studies have shown that people over the age of 50 with a high risk of osteoporotic fractures represented more than 150 million people worldwide with 137 million women [6]. This number is expected to exceed 300 million by 2040 [6]. Fragility fractures lead to more than half a million hospitalizations each year in North America alone, with an annual direct cost, which has been estimated to be $\$ 17$ billion dollars in 2005. This cost is expected to rise by almost $50 \%$ by 2025 [7]. Overall, the early 
identification of bone fragility risk is a major health issue [8]. In the clinical context, bone disorders are usually assessed using dual-energy X-ray absorptiometry (DXA), which is able to assess the bone mineral density (BMD). The BMD score is then compared to a reference range of values calculated in healthy (25-35 years old) volunteers taking into account sex and ethnicity. Accordingly, a score (T-score) is generated indicating how far, in terms of SD (standard deviation), the measured BMD is from the reference values. A T-score between -1 and -2.5 indicates a low bone mass or osteopenia while a value lower than -2.5 is indicative of osteoporosis. The corresponding method has good sensitivity (around $88 \%$ for both men and post-menopausal women), but the specificity is poor (around $41 \%$ for post-menopausal women and 55\% for men) [9] resulting in a low clinical diagnostic accuracy (70\%) [10]. In addition, DXA measurements do not take into consideration microarchitectural alterations, which have also been recognized as part of the structural picture in osteoporosis. Of interest, bone microarchitecture can be assessed using quantitative computed tomography (qCT) [11,12]. Given that both DXA and qCT are both radiative imaging techniques, non-radiative alternatives would be of great interest. Over the last decades, magnetic resonance imaging (MRI) [13-15] has been indicated as a non-ionizing and non-invasive technique.

Using MRI, a large number of studies have attempted to assess bone microarchitecture in bone disorders and more particularly in osteoporosis [16-19]. The corresponding studies have been conducted at different magnetic field strengths, using different Radio Frequency coils and pulse sequences. Although, the results were compelling, the sensitivity of the corresponding microarchitecture metrics for diagnostic purposes and the assessment of the disease severity is still a matter of debate.

On the basis of a comparative survey of MRI, computed tomography, and DXA-based metrics, we intended to address the issues related to the diagnostic potential of the corresponding metrics and their capacity to predict disease severity. The final section will be devoted to potential perspectives offered by magnetic resonance spectroscopy (MRS) and chemical shift encoding (CSE-MRI), solid-state MRI, and quantitative susceptibility mapping (QSM).

\subsection{Bone Microstructure}

Bone is a multiphase material composed of a solid phase and a viscoelastic component. The solid phase is considered as hierarchical, anisotropic, and heterogeneous and is composed of $65 \%$ of inorganic matrix (mostly calcium hydroxyapatite crystals) and $35 \%$ of organic matrix (type I collagen, proteoglycans, and bound water) [20]. While the inorganic matrix is characterized by a high rigidity, a high resistivity, and an elastic behavior, the organic matrix is deformable thereby providing the tissue with tensile strength. Due to the combination of these two materials, bone tissue is simultaneously deformable and rigid [21]. The solid phase creates a shell for the bone marrow, which is the viscoelastic component. The bone marrow on the other hand has a double function. It provides nutriments to the solid phase allowing higher regenerative rate and is able, due to its viscoelastic properties, to spread the dynamics of an impulsive action, reducing the risk of fractures due to impacts [22]. Bone tissue is composed of both trabecular and cortical bone phases. Cortical bone covers the whole surface of the bone. It is compact, dense, and characterized by overlapped and parallel lamellae, which provide a large resistivity [20]. Trabecular bone is the inner compartment of bone tissue. It is composed of $25 \%$ of bone and $75 \%$ of marrow [23]. At the microstructural level, trabecular bone appears as a complex 3D network of interconnected trabeculae rods and plates responsible for tissue resistance to loading forces. The bone inner architecture is an important contributor to bone strength independent of bone mass [20]. It is characterized by a high porosity so that trabecular bone is lighter and less dense than cortical bone. In fact, cortical bone mainly works in compression while trabecular bone principally works in flexion and torsion reaching a higher area under the stress-strain curve [23].

Bone is actually a dynamic porous structure and this porosity can change as a result of pathological processes but also as an adaptive response to mechanical or physiological 
stimuli. This change in both cortical and trabecular bone porosity can strongly affect the corresponding mechanical properties [23].

\section{Bone Pathologies and Clinical Approach}

\subsection{Principal Bone Pathologies}

Pathologies of the bone microstructure are quite common. Musculoskeletal (MSK) complaints are the second most common reason for consulting a medical doctor and account for $10-20 \%$ of primary care visits [4]. They are also among the leading causes of long-term disability and the leading cause for long-term absence from work in numerous countries [4,24]. Worldwide, the total number of MSK disability adjusted life years (DALYs) significantly increased from 80.2 million in 2000 to 107.9 million in $2015(p<0.001)$ with the total number of MSK years lived with disability (YLDs) increasing from 77.4 million to 103.8 million. Overall, MSK diseases represent the second cause of YLDs worldwide [25].

The most common pathology related to bone microstructure alterations is osteoporosis in which bone density and volume of bone segments or specific bone regions can be progressively reduced. Patients with osteoporosis are at high risk of having one or more fragility fractures, which eventually lead to a physical debilitation and potentially to a downward spiral in physical and mental health. Johnell et al. reported that 9 million osteoporotic fractures occurred in 2000, 1.6 million in the hip, 1.7 million in the wrist, and 1.4 million in the vertebrae [5]. Only in the five largest countries in Europe plus Sweden (EU6), the number of fragility fractures were estimated at 2.7 million in 2017 with an associated annual cost of $€ 37.5$ billion and both fragility fractures and associated annual cost are expected to increase by $23 \%$ in 2030 [26]. A large Chinese epidemiological survey using DXA among people aged fifty years or older demonstrated the prevalence of osteoporosis in males (6.46\%) than females $(29.13 \%)$ meaning that there are 10 million men and 40 million women with osteoporosis only in China [27]. The current DALYs per 100 individuals age 50 years or more were estimated at 21 years, which is higher than the estimates for stroke or chronic obstructive pulmonary disease [26]. Moreover, it has been reported that if all patients who fracture in the EU6 were enrolled into fracture liaison services, at least 19,000 fractures every year might be avoided [26]. Finally, Kemmak et al. reported that the direct annual cost of treating osteoporotic fractures of people on average is between 5000 and 6500 billion USD in Canada, Europe, and USA alone, not taking into account indirect costs, i.e., disability and loss of productivity [28].

Osteoporosis may be linked to ageing, particularly in postmenopausal women, or can occur as a result of specific conditions, i.e., diabetes, anorexia nervosa, and obesity or treatments, i.e., corticosteroid. Indeed, corticosteroid-induced osteoporosis is the most common form of secondary osteoporosis and the first cause in young people. Bone loss occurs early after the initiation of corticosteroid therapy and is correlated to dose and treatment duration [29]. Fragility fractures have been associated with early mortality and increased morbidity having a significant effect on the quality of life of both patients affected by diabetes [30-32], anorexia nervosa [33,34], and obesity [35-37].

Additionally, a number of childhood diseases cause rickets, a physical condition resulting from a delayed calcium phosphate mineral deposition in growing bones, which may lead to skeletal deformities [38]. In adults, the equivalent disease is called osteomalacia and may have devastating consequences if not diagnosed and treated [39,40]. Patients with chronic renal disease are at risk of developing a complex bone disease known as renal osteodystrophy, which is responsible for an increasing bone resorption due to an increased osteoclast activity [11,41].

Paget's disease is a chronic progressive bone disorder occurring in middle-aged or older adults and which commonly affect spine, pelvis, legs, or skull [42,43]. The most likely etiology is a slow paramyxoviral viral infection in generally susceptible individuals, however the exact cause is unknown [44]. It appears to arise more or less simultaneously in one or more skeletal sites, remaining restricted there. In long bones the disease first appears in the region of the proximal epiphysis and advances along the shaft at a rate of 
$8 \mathrm{~mm} / \mathrm{yr}$ [45]. Paget's disease is initially characterized by bone resorption, disorganized bone deposition, resulting in pathological bone remodeling where the osteoclastic activity is predominant, is then followed by a mixed phase of osteoclast and osteoblast with osteoblasts prevailing, and end with an inactive phase where the osteoblastic activity declines [42]. The leading edge of this advance is often visible as a V-shaped "lytic wedge" reflecting osteoclastic resorption [45]. Moreover, it has been noticed that an elevated serum alkaline phosphatase level correlated with the disease activity [44]. Diagnosis and follow-up are usually based on imaging modalities in order to assess disease status, bone microarchitecture and metabolic activity. MRI is invaluable for the assessment of complications, i.e., spinal stenosis and sarcomatous degeneration [42]. An early diagnosis of this disease can minimize the impact on the patient quality of life [46].

Many genetic and developmental disorders can affect the skeleton. Among them, the most common is the osteogenesis imperfecta [47]. Osteogenesis Imperfecta (OI) is a systemic connective tissue disorder characterized by low bone mass and bone fragility causing significant morbidity due to pain, immobility, skeletal deformities, and growth deficiency. Moreover, it is the most prevalent heritable bone fragility disorder in children [47-51]. OI is a skeletal dysplasia characterized by bone fragility and high incidence of fractures that may occur with minimal or no trauma $[48,50]$. Fractures may involve atypical locations. Vertebral fractures occur in about $70 \%$ of OI patients. Joint hypermobility is also common and gray or blue scleral hue is a predominant OI feature $[48,50]$. Moreover, severe OI may present prenatally by detection of in utero fractures and shortening of long bones on prenatal ultrasound $[47,48,50]$. OI is currently diagnosed using patient history, clinical examination, lumbar spine BMD, bone biochemistry, and image analysis (CT and/or MRI scans) $[47,50,52]$. Interestingly, Ashinsky et al. have shown that multiparametric classification using quantitative MRI could detect at the skin level differences between OI patients and unaffected individuals, suggesting the potential of MRI for the clinical OI diagnosis [53]. However, the molecular diagnosis using DNA sequence analysis can pinpoint the exact OI cause and provide information about the recurrence risk to affected individuals and their families [47,49]. There is no cure for OI and among the clinical and chirurgical therapies (largely supportive at present), the bisphosphonate therapy has shown remarkable effect where treatment efficacy and follow ups are usually assessed though image analysis [47,52,54].

Lastly, some skeletal disorders can result from primary or secondary tumors. Primary bone tumors are rare, accounting for $<0.2 \%$ of malignant neoplasms registered in the EUROCARE (European Cancer Registry based study on survival and care of cancer patients) database [55], and in particular osteosarcoma (OS) represents $<1 \%$ of all cancers diagnosed in the United States [56]. OS is classically described as a high grade spindle shaped neoplasm with malignant cells that produce osteoid [56]. However, OS is the first primary cancer of bone (incidence: 0.3 per 100,000 per year) with a relatively high incidence in the second decade of life (incidence: $0.8-1.1$ per 100,000 per year at age 15-19 years) [55]. Most of the OSs of younger patients arise in the metaphysis of long bones with the most common sites being the extremities (distal femur, proximal tibia, and proximal humerus) [56], while the axial tumor sites increases with age. Conventional radiography is the first radiological investigation. However, MRI investigation of the whole compartment with adjacent joints is regarded today as the best modality for local staging of extremities and pelvic tumors [55,57]. The final diagnosis as for the disease grading is based on biopsy, histology, and molecular assessment. Curative treatment consists of chemotherapy and surgery [55,57]. In the case of chemotherapy treatment, dynamic MRI is reliable for the evaluation of changes in tumor vascularity $[57,58]$.

\subsection{Clinical Approach}

The clinical evaluation of bone status is mainly based on the dual-energy X-ray absorptiometry (DXA), which gives information about the bone mineral density (BMD). The whole body or a bone segment is scanned using X-rays and a 2D projection of bone density 
is evaluated using a standard reference. Although this technique has been classified as being minimally invasive, the radiation deposition dose for a whole body DXA examination is $0.0042 \mathrm{mSv}$, and can reach up to $0.009 \mathrm{mSv}$ and $0.013 \mathrm{mSv}$ respectively for the hip and the spine examination [59]. DXA is the most common screening evaluation test for osteoporosis and body composition (whole body percent fat). Since the proportion of cortical bone is often larger, DXA is more sensitive to the presence and quality of the cortical bone. DXA can then be considered as poorly sensitive to trabecular bone alterations. Accordingly, recent studies have shown that DXA is not well suited to discriminate between patients with and without fragility fractures while this would be possible with quantitative microarchitecture analysis [18,60-62].

For clinical applications, bone inner morphology can be assessed using quantitative computed tomography (qCT), an X-ray based technique, which could be used to assess central and peripheral skeletal sites. The acquired volumes of interests are reconstructed from a stack of images, which can reach $n=900$ images for a $45-\mathrm{cm}$ abdominal-thorax scan, with a radiation deposition dose of $0.06-0.3 \mathrm{mSv} /$ image. On that basis, this technique is considered as highly radiative $[59,63]$. On the contrary to DXA, the tomographic reconstruction and the resolution power of $\mathrm{qCT}$ can provide information related to the inner bone morphology. For deep bone segments, the corresponding image resolution ranges between 0.160 and $0.300 \mathrm{~mm}$ due to radiations issues [64]. For bone extremities, i.e., radii and tibiae, $\mathrm{qCT}$ can be replaced by high-resolution peripheral computed tomography (HR-pQCT), which provides a higher resolution, i.e., between 0.040 and $0.150 \mathrm{~mm}[12,64]$. Due to a low benefit-risk ratio, qCT and HR-pQCT are not currently used for the diagnosis of bone diseases in clinical practice.

\section{MRI Based Approach}

A non-invasive alternative to DXA and qCT could be MRI. Over the last two decades, a large number of studies have intended to assess bone microstructure using MRI. The initial investigations have been performed using T1-weighted spin echo sequences characterized by short TR $(<1200 \mathrm{~ms})$ and short TE $(<25 \mathrm{~ms})$ in distal radius and calcaneus [16,65-67]. Due to technical advances, tibiae $[17,68,69]$, spine $[65,70]$, and proximal femur $[18,60,71,72]$ have been investigated. MRI of trabecular microstructure can be obtained by imaging the marrow phase inside the bone segment, which appears as a hyperintense signal in conventional MR images. Using higher field MRI, i.e., 3T one can expect an increased signal to noise ratio (SNR), which can be translated either in a reduced acquisition time or an increased image resolution. Over the last decades, due to the higher availability of high-field (HF) MRI scanners, a large number of studies have been dedicated to the MRI assessment of osteoporosis [17,18,60,62,69,71,72]. Very recently, clinical FDA and CEapproved ultra-high field (i.e., 7T UHF) MRI scanners with announced MSK applications have become available. Their clinical availability is still poor and the coming results will be of utmost importance to decide about the future of UHF MRI for clinical purposes.

Using MRI, the most common extrapolated features are the bone volume fraction (BVF), the trabecular thickness (Tb.Th), spacing (Tb.Sp), and number (Tb.N) [18,62].

\subsection{Technical Considerations for Clinical Usefulness}

A signal to noise ratio (SNR) of 10 has been reported as the minimum value for the investigation of bone microarchitecture [73]. The scan time considered acceptable for clinical examination has to range between 10 and $15 \mathrm{~min}$. As a result the minimum voxel size, which has been obtained at $1.5 \mathrm{~T}$ was between 0.135 and $0.250 \mathrm{~mm}$ while the slice thickness was between 0.3 and $1.5 \mathrm{~mm}$. One has to keep in mind that SNR would be higher for superficial anatomical sites (radius or calcaneus compared to deeper anatomical sites, e.g., proximal femur) leading to higher resolution or shorter acquisition time. Moreover, SNR can be increased at higher field strengths and/or using multichannel coils [73-76].

MRI pulse sequences such as gradient recalled echo (GRE) and spin echo (SE) have also been tested at different field strengths $[17,71,77]$. It has been shown that $\mathrm{SE}$ sequences 
were less susceptible to partial volume effects as compared to GRE sequences and that GRE were more sensitive to trabecular broadening than SE. These results indicate that SE sequences would provide more accurate results regarding trabecular characteristics $[17,77]$. However, the use of these pulse sequences might be problematic using ultra-high field (UHF) MRI considering power-deposition issues.

A list of the main literature references, scanned regions, sequences, and principal MRI setup parameters is reported in Table 1.

\subsection{Microstructure Investigation}

In the majority of MRI literature, the morphological parameters that are reported are BVF, Tb.Th, Tb.Sp, and Tb.N $[71,77,78]$. In addition, some groups have proposed some other features such as an erosion index, trabecular rod- and plate-like structures, trabecular plate-to-rod ratio, trabecular isolation, and fractal lacunarity [18,79].

These microarchitectural parameters have been generated from the post-processing of both 2D and 3D images. The corresponding analyses were performed in binarized images or in original grey level intensities. All these approaches have tried to take into account partial volume effects occurring given the poor resolution of MRI as compared to the trabeculae dimension $[62,80,81]$. So far, no standard reference has been suggested.

Studies performed at different MRI field strength in postmenopausal woman with fragility fractures have illustrated microstructural alterations (reduced BVF and increased $\mathrm{Tb} . \mathrm{Sp}$ ) whereas DXA T-scores were unchanged. In a study conducted in distal radii at 1.5T, Kijowsky et al. showed that post-menopausal woman had a slightly lower $(-9 \%)$ bone volume fraction and a higher erosion index $(+17 \%)$ compared to controls [82]. Krug et al. in a study conducted on the proximal femurs of six healthy males and females using both 1.5T and 3T MRI showed good correlation ( $\mathrm{r}$ up to 0.86 ) between structural parameters obtained from the two different field strengths. However, they reported that bone structure of the proximal femur was substantially better depicted at 3T than 1.5T [71]. Microstructure alterations have been reported in a large variety of cases including chronic kidney disease (CKD) [11,41], HIV-infection [83] glucocorticoid-induced osteoporosis [72], or disuse osteoporosis [84].

In a 3T MRI study conducted in distal tibiae of 20 patients with CKD, Ruderman et al. reported trabecular deterioration together with reduced cortical thickness [41]. Moreover, a study conducted on 30 patients affected by end stage renal disease (ESRD) it has been shown that $\mathrm{Tb} . \mathrm{N}, \mathrm{Tb}$.Th, and whole bone stiffness were significantly lower $(p<0.01)$ is ESRD compared to controls [85]. A similar study conducted on distal tibiae of 11 kidney transplant recipient patients have high-lightened post-transplant deterioration in trabecular bone quality [86]. In a study conducted in proximal femurs at 3T, glucocorticoid treated patients had a largely reduced $(-50.3 \%)$ Tb.N, trabecular plate-to-rod ratio $(-20.1 \%)$, and a largely increased $(+191 \%) \mathrm{Tb} . S p$ [72]. Patients with a disuse osteoporosis displayed similar anomalies for BVF $(-30 \%)$, Tb.N $(-21 \%)$, Tb.Th $(-12 \%)$, and Tb.Sp $(+48 \%)$ [84]. Chang et al. [18] further supported and extended these results in a study conducted in distal femur at 7T. In 31 subjects with fragility fractures, they reported a lower BVF $(-3 \%)$, Tb.N (-6\%), and erosion index (-6\%). Moreover, in a 7T MRI study conducted in the distal radius of 24 women, Griffin et al. reported a trabecular bone microarchitecture gradient with an overall higher quality $(+123 \% \mathrm{BVF},+16 \% \mathrm{~Tb} . \mathrm{N})$ distally (epiphysis) than proximally (diaphysis) [87].

Ultra-high field MRI can provide images with a smaller pixel size $(0.156 \mathrm{~mm} \times 0.156 \mathrm{~mm})$ as compared to the resolution achieved at lower field strength $(0.234 \mathrm{~mm} \times 0.234 \mathrm{~mm}$ for example at 3T [17,71]). In a dual 3T-7T study conducted in distal tibiae of 10 healthy volunteers, Krug et al. reported that metrics computed at higher field strength were different than those quantified from 3T MR images. More specifically, UHF measurements illustrated increased BVF $(+22 \%)$ and Tb.Th $(+25 \%)$ whereas Tb.Sp $(-21 \%)$ and Tb.N $(-4 \%)$ were both decreased [88]. These results suggest a higher discriminative power of UHF MRI for trabecular features. 
Table 1. List of the main magnetic resonance imaging (MRI) parameters and sequences.

\begin{tabular}{|c|c|c|c|c|c|c|c|c|c|c|}
\hline $\begin{array}{l}\text { Anatomical } \\
\text { Site }\end{array}$ & Clinical History & $\begin{array}{c}\text { Specimen } \\
\text { /Patient }\end{array}$ & Acq. Time & $\begin{array}{l}\text { S1. Thickness } \\
{[\mathrm{mm}][\mathrm{mm}]}\end{array}$ & Pix. Size [mm] & FOV $[\mathrm{mm}]$ & Sequence & Main Field & $\mathbf{N}^{\circ}$ & Reference \\
\hline distal radii & type 2 diabetes & patient & $12 \min 9 s$ & 1 & $0.195 \times 0.195$ & $100 \times 100$ & FSE & $1 \mathrm{~T}$ & [78] & Pritchard et al. \\
\hline calcaneus & $\begin{array}{l}\text { osteoporotic hip } \\
\text { fractures }\end{array}$ & patient & $15 \min 15 s$ & 0.5 & $0.195 \times 0.195$ & $100 \times 100$ & GE & $1.5 \mathrm{~T}$ & [67] & Link et al. \\
\hline distal radii & healthy & patient & $16 \min 25 \mathrm{~s}$ & 0.5 & $0.156 \times 0.156$ & $80 \times 45$ & 3D FLASE & $1.5 \mathrm{~T}$ & {$[75]$} & Techawiboonwong et al. \\
\hline distal radii & healthy & patient & $3 \min 15 s$ & 0.5 & $0.156 \times 0.156$ & $80 \times 45$ & 3D SSFP & $1.5 \mathrm{~T}$ & [75] & Techawiboonwong et al. \\
\hline distal radii & NA & specimen & $15 \mathrm{~min}$ & 0.3 & $0.156 \times 0.156$ & 80 & GE & $1.5 \mathrm{~T}$ & [13] & Majumdar et al. \\
\hline lumbar spine & osteoporotic & patient & $16 \mathrm{~min}$ & 0.7 & $0.156 \times 0.156$ & $80 \times 80$ & GE & $1.5 \mathrm{~T}$ & [65] & Majumdar et al. \\
\hline distal radii & hip fractures & patient & NA & 0.5 & $0.156 \times 0.156$ & $80 \times 80$ & GE & $1.5 \mathrm{~T}$ & [16] & Majumdar et al. \\
\hline prox. femur & NA & specimen & $\begin{array}{l}74 \min (1) \\
27 \min (2)\end{array}$ & $0.3(1) 0.9(2)$ & $0.195 \times 0.195$ & $75 \times 100$ & SE & $1.5 \mathrm{~T}$ & [80] & Link et al. \\
\hline prox. femur & healthy & patient & $6 \min 12 \mathrm{~s}$ & 1.5 & $0.234 \times 0.234$ & NA & 3D FIESTA & $1.5 \mathrm{~T}$ & [71] & Krug et al. \\
\hline distal tibiae & NA & specimen & $40 \mathrm{~min}$ & 0.16 & $0.160 \times 0.160$ & $70 \times 63$ & 3D FLASE & $1.5 \mathrm{~T}$ & [81] & Rajapakse et al. \\
\hline lumbar spine & NA & specimen & $15 \min 23 \mathrm{~s}$ & 0.41 & $0.137 \times 0.137$ & $70 \times 64 \times 13$ & 3D FLASE & $1.5 \mathrm{~T}$ & [70] & Rajapakse et al. \\
\hline $\begin{array}{l}\text { distal radii(1) } \\
\text { distal tibiae(2) }\end{array}$ & $\begin{array}{l}\text { osteopenic and } \\
\text { osteoporotic }\end{array}$ & patient & $\begin{array}{l}12 \min (1) \\
16 \min (2)\end{array}$ & 0.4 & $0.137 \times 0.137$ & $70 \times 40(1) 70 \times 50(2)$ & 3D FLASE & $1.5 \mathrm{~T}$ & [66] & Ladinsky et al. \\
\hline distal femur & $\begin{array}{l}\text { cerebral palsy } \\
\text { (children) }\end{array}$ & patient & $9 \min 52 \mathrm{~s}$ & 0.7 & $0.175 \times 0.175$ & 90 & 3D fast GE & $1.5 \mathrm{~T}$ & [82] & Modlesky et al. \\
\hline $\begin{array}{c}\text { distal radii(1) } \\
\text { distal tibi.ae(2) }\end{array}$ & osteoporotic & patient & $\begin{array}{l}12 \min (1) \\
16 \min (2)\end{array}$ & 0.41 & $0.137 \times 0.137$ & $\begin{aligned} 70 & \times 40 \times 13(1) 70 \\
& \times 50 \times 13(2)\end{aligned}$ & 3D FLASE & $1.5 \mathrm{~T}$ & [83] & Rajapakse et al. \\
\hline $\begin{array}{l}\text { prox. femur } \\
\text { prox. femur }\end{array}$ & $\begin{array}{l}\text { NA } \\
\text { healthy }\end{array}$ & $\begin{array}{l}\text { specimen } \\
\text { patient }\end{array}$ & $\begin{array}{l}16 \min 55 \mathrm{~s} \\
12 \min 43 \mathrm{~s}\end{array}$ & $\begin{array}{l}1.1 \\
1.5\end{array}$ & $\begin{array}{c}0.21 \times 0.21 \\
0.234 \times 0.235\end{array}$ & $\begin{array}{l}120 \\
\text { NA }\end{array}$ & $\begin{array}{c}\text { TSE } \\
\text { 3D FIESTA }\end{array}$ & $\begin{array}{l}3 \mathrm{~T} \\
3 \mathrm{~T}\end{array}$ & $\begin{array}{l}{[84]} \\
{[71]}\end{array}$ & $\begin{array}{l}\text { Soldati et al. } \\
\text { Krug et al. }\end{array}$ \\
\hline $\begin{array}{l}\text { distal radii, } \\
\text { distal tibiae }\end{array}$ & NA & specimen & $<10 \min$ & 0.5 & $0.156 \times 0.156$ & NA & GE & $3 \mathrm{~T}$ & [77] & Krug et al. \\
\hline $\begin{array}{l}\text { distal radii, } \\
\text { distal tibiae }\end{array}$ & NA & specimen & $<10$ min & 0.5 & $0.156 \times 0.156$ & NA & GRE & $3 \mathrm{~T}$ & [77] & Krug et al. \\
\hline $\begin{array}{l}\text { distal radii, } \\
\text { distal tibiae }\end{array}$ & NA & specimen & $<10 \min$ & 0.5 & $0.156 \times 0.156$ & NA & SE & $3 \mathrm{~T}$ & [77] & Krug et al. \\
\hline distal tibiae & osteoporotic & patient & $15 \mathrm{~min}$ & 0.41 & $0.137 \times 0.137$ & $70 \times 64 \times 13$ & 3D FLASE & $3 \mathrm{~T}$ & [69] & Zhang et al. \\
\hline prox. femur & $\begin{array}{l}\text { fragility } \\
\text { fractured }\end{array}$ & patient & $25 \min 30 s$ & 1.5 & $0.234 \times 0.234$ & 120 & FLASH & $3 \mathrm{~T}$ & {$[60]$} & Chang et al. \\
\hline prox. femur & $\begin{array}{l}\text { long-term } \\
\text { glucocorticoid }\end{array}$ & patient & $15 \min 18 \mathrm{~s}$ & 1.5 & $0.234 \times 0.234$ & 100 & FLASH & $3 \mathrm{~T}$ & [72] & Chang et al. \\
\hline distal radii & $\begin{array}{l}\text { HR+ breast } \\
\text { cancer }\end{array}$ & patient & $7 \mathrm{~min}$ & 0.34 & $0.170 \times 0.170$ & 65 & GE & $3 \mathrm{~T}$ & [85] & Baum et al. \\
\hline $\begin{array}{l}\text { distal femur } \\
\text { prox. tibia }\end{array}$ & $\begin{array}{l}\text { osteoarthritis } \\
\text { osteoarthritis }\end{array}$ & $\begin{array}{l}\text { patient } \\
\text { patient }\end{array}$ & $\begin{array}{l}9 \min 18 \mathrm{~s} \\
3 \min \end{array}$ & $\begin{array}{c}1 \\
2.8\end{array}$ & $\begin{array}{l}0.180 \times 0.180 \\
0.230 \times 0.240\end{array}$ & $\begin{array}{c}100 \\
120 \times 123\end{array}$ & $\begin{array}{l}\text { 3D B-FFE } \\
\text { SE }\end{array}$ & $\begin{array}{l}3 \mathrm{~T} \\
\text { 3T }\end{array}$ & $\begin{array}{l}{[86]} \\
{[87]}\end{array}$ & $\begin{array}{c}\text { Liu et al. } \\
\text { MacKey et al. }\end{array}$ \\
\hline
\end{tabular}


Table 1. Cont.

\begin{tabular}{|c|c|c|c|c|c|c|c|c|c|c|}
\hline $\begin{array}{l}\text { Anatomical } \\
\text { Site }\end{array}$ & Clinical History & $\begin{array}{l}\text { Specimen } \\
\text { /Patient }\end{array}$ & Acq. Time & $\begin{array}{l}\text { S1. Thickness } \\
{[\mathrm{mm}][\mathrm{mm}]}\end{array}$ & Pix. Size $[\mathrm{mm}]$ & FOV $[\mathrm{mm}]$ & Sequence & Main Field & $\mathbf{N}^{\circ}$ & Reference \\
\hline $\begin{array}{l}\text { prox. tibia, } \\
\text { distal femur }\end{array}$ & osteoarthritis & patient & NA & 1 & $0.195 \times 0.195$ & 100 & FIESTA-c & $3 \mathrm{~T}$ & [88] & Chiba et al. \\
\hline $\begin{array}{l}\text { prox. tibia, } \\
\text { distal femur }\end{array}$ & osteoarthritis & patient & NA & 1 & $0.195 \times 0.195$ & 160 & SPGR & $3 \mathrm{~T}$ & [88] & Chiba et al. \\
\hline distal tibiae & NA & specimen & $7 \mathrm{~min}$ & 0.41 & $0.137 \times 0.137$ & $70 \times 53 \times 13$ & 3D FLASE & $3 \mathrm{~T}$ & [19] & Rajapakse et al. \\
\hline prox. femur & NA & specimen & $16 \min 45 s$ & 1.5 & $0.13 \times 0.13$ & 130 & TSE & $7 \mathrm{~T}$ & [89] & Soldati et al. \\
\hline prox. femur & NA & specimen & $37 \min 36 s$ & 0.5 & $0.170 \times 0.170$ & $140 \times 140$ & GRE & $7 \mathrm{~T}$ & [62] & Guenoun et al. \\
\hline distal tibiae & healthy & patient & $19 \min 10 \mathrm{~s}$ & 0.5 & $0.156 \times 0.156$ & NA & $\mathrm{SE}$ & $7 \mathrm{~T}$ & [17] & Krug et al. \\
\hline $\begin{array}{c}\text { vertebrae } \\
\text { (1 axial, } \\
2 \text { sagittal) }\end{array}$ & NA & specimen & $\begin{array}{l}34 \min (1) \\
51 \min (2)\end{array}$ & $0.4(1) 0.5$ (2) & $0.170 \times 0.170$ & $140 \times 140$ & GRE & $7 \mathrm{~T}$ & [90] & Guenoun et al. \\
\hline distal femur & $\begin{array}{l}\text { fragility } \\
\text { fractured }\end{array}$ & patient & $7 \min 9 s$ & 1 & $0.234 \times 0.234$ & 120 & FLASH & $7 \mathrm{~T}$ & [18] & Chang et al. \\
\hline $\begin{array}{l}\text { femurs, tibiae, } \\
\text { vertebrae }\end{array}$ & NA & specimen & $120 \mathrm{~min}$ & 0.05 & $0.05 \times 0.05$ & $6.4 \times 6.4 \times 25.6$ & SE & $9.4 \mathrm{~T}$ & [91] & Rajapakse et al. \\
\hline
\end{tabular}




\subsection{Microstructure vs. DXA}

In a study conducted in 32 postmenopausal women, Kang et al. showed a good correlation between DXA-based BMD and MRI T2 and T2 * in calcaneus $(\mathrm{r}=-0.8$, $p<0.001)$ and spine $(r=-0.53, p=0.002)$ [89]. Similar results have been reported for the femoral neck $[65,90]$ with a good correlation $(r=0.74, p<0.001)$ between DXA-based BMD and $\mathrm{T} 2 *$ values [91]. T2* relaxation time illustrates the susceptibility differences between trabecular and bone marrow leading to signal loss due to magnetic field inhomogeneities. MRI-derived T2 * has been shown to correlate with DXA results in several anatomical areas such as calcaneus, distal radius, and Ward's area in the femoral neck [92,93]. Based on $\mathrm{T} 2 *$ measurements, Schmeel et al. reported a significant difference between benign and malignant neoplastic vertebral compression fractures (VCFs). A 72\% diagnostic accuracy was computed [94]. Furthermore, a strong negative correlation was found between the pelvic bone marrow adipose tissue (BMAT) calculated in 56 healthy women using MRI and the corresponding DXA-based BMD $(\mathrm{r}=-0.646, p<0.001)$ [95]. The negative correlation indicates that patients with decreased bone mineral density are characterized by an increased fat content in bone marrow [95-97].

Based on highly resolved MR images (0.150-0.300 mm in-plane pixel size), Chang et al. showed a lack of significant correlation between DXA-computed BMD T-scores and MRI computed microarchitectural parameters in the femoral neck in both controls and glucocorticoid-treated patients $[72,98]$. Similar results were also reported more recently in subchondral tibiae [61], proximal femurs [62,81], vertebrae [99], and on patients affected by diabetes [31,32]. Guenoun et al. reported that the combination of BVF and BMD was able to improve the prediction of the failure stress (from $\mathrm{r}^{2}=0.384$ for BMD alone to $\mathrm{r}^{2}=0.414$ ). All the presented results suggest that although density and structure metrics illustrate bone quality, microarchitectural parameters provide additional information regarding skeletal fragility.

\subsection{Voxel Size and Microstructure}

Results from the literature showed that image resolution is a key parameter for the assessment of bone microarchitecture. Importantly, a distinction must be made between in-plane and through-planes resolution. For specific oriented plane (mostly perpendicular to the trabecular), an in-plane MRI pixel size in the same order of magnitude than $\mathrm{Tb}$.Th dimension is enough to measure morphological parameters similar to those extrapolated using gold standard method and so both ex vivo $(\mu \mathrm{CT})[81,100]$ and in vivo (HR-pQCT) [77]. If one intends to assess bone microstructure using small isovolumetric voxels $(0.15 \mathrm{~mm})$, close to the actual thickness of the trabeculae, with an acceptable SNR, acquisition times would exceed the in vivo acceptable duration. One can increase the SNR and reduce the acquisition time with an increased slice thickness while keeping the plane pixel size constant. Accordingly, the radius morphological parameters computed from similar in-plane pixel sizes and different slice thicknesses $(0.156 \mathrm{~mm} \times 0.156 \mathrm{~mm} \times 0.3 \mathrm{~mm}$ [13], $0.156 \mathrm{~mm} \times 0.156 \mathrm{~mm} \times 0.5 \mathrm{~mm}$ [16,101], $0.156 \mathrm{~mm} \times 0.156 \mathrm{~mm} \times 0.7 \mathrm{~mm}$ [65], and $0.153 \mathrm{~mm} \times 0.153 \mathrm{~mm} \times 0.9 \mathrm{~mm}$ [102]) were comparable. In fact, the bone inner microarchitecture appeared to be a mixture of oriented plates- and rod-like structures. The parallel trabecular plates structures are separated by bone marrow and are perpendicular to the coronal plane [103]. On that basis, increasing the in-plane pixel size should provide more accurate results independently of the slice thickness. As reported by Mulder et al., the calculated volume of ellipsoid at high resolution $(0.1 \mathrm{~mm} \times 0.1 \mathrm{~mm})$ is independent from the anisotropy factor but related to the orientation [104].

Different studies performed in distal radii at 1.5T, using similar in-plane pixel size and using different slice thicknesses above $0.3 \mathrm{~mm}$, reported comparable morphological results $[13,16,82]$. However, in a study conducted by Majumdar et al. in 39 distal radii specimens acquired using 1.5T MRI and contact radiograph, 0.9-mm thick MR images performed better than those obtained from 0.3-mm images. This was explained with the significantly higher SNR (18.2 in 0.9-mm thick images and 9.3 in 0.3-mm sections) [102]. Similar results were obtained 
in vivo in distal radii scanned at $1.5 \mathrm{~T}(0.156 \mathrm{~mm} \times 0.156 \mathrm{~mm} \times 0.5 \mathrm{~mm})$ with an acceptable SNR around 10 [75]. Moreover, wrists and distal tibiae scanned in patients using 1.5T with pixel sizes in the same range of trabecular thickness $(0.156 \mathrm{~mm} \times 0.156 \mathrm{~mm} \times 0.410 \mathrm{~mm}[66]$ and $0.137 \mathrm{~mm} \times 0.137 \mathrm{~mm} \times 0.410 \mathrm{~mm}$ [105]) reporting lower acquisition time for wrist (12 $\mathrm{min})$ than for tibiae (16 $\mathrm{min}$ ) and good image quality in both anatomical regions. In a second study conducted by Majumdar et al., 31 cadaveric proximal femurs were scanned at 1.5T with an in-plane pixel size of $0.195 \times 0.195$ and comparing two different slice thicknesses (0.9 and $0.3 \mathrm{~mm}$ ). The SNR achieved was 25.2 and 13.8 for the larger and smaller slice thickness respectively. The corresponding acquisition times were very long (27:19 and 73:14 min), i.e., much longer than what could be accepted in clinics [106].

The knee articulation has also been assessed in the study of Rajapakse et al., 17 distal tibiae specimens were scanned at $3 \mathrm{~T}(0.137 \mathrm{~mm} \times 0.137 \mathrm{~mm} \times 0.410 \mathrm{~mm})$ in $7 \mathrm{~min}$ [19]. These results where extended in vivo by Zhang et al., in the distal tibiae of 20 postmenopausal women with osteoporosis. The scanning time using 3T MRI $(0.137 \mathrm{~mm} \times 0.137 \mathrm{~mm} \times 0.410 \mathrm{~mm})$ was less than $15 \mathrm{~min}$ [69]. Krug et al. further confirmed these results in a study comparing 3 T MRI $(0.156 \mathrm{~mm} \times 0.156 \mathrm{~mm} \times 0.5 \mathrm{~mm})$ and X-ray based techniques both ex vivo (5 tibiae and 3 radii) and in vivo (5 radii and 6 tibiae). While the scanning time was less than $10 \mathrm{~min}$, correlations were reported between both methods and so for the whole set of parameters, i.e., BVF ( $r=0.83)$ and Tb.Sp $(r=0.7)$ [107]. Liu et al. also reported 3T MR images (pixel size $0.180 \mathrm{~mm} \times 0.180 \mathrm{~mm}$, acq. time 9:18 min) of 92 distal femurs divided in three groups (without osteoarthritis, mild osteoarthritis, and severe osteoarthritis) reporting progressively lower BVF and higher erosion index from healthy patients to those affected by severe osteoarthritis [108], extending previous results [109-111].

\subsection{Main Magnetic Field Strength Effect}

The technical advantages of moving from 1.5T to 3T or 7T MR scanners were clearly visible in the acquisition of deeper anatomical sites keeping the spatial pixel size in the same order of the trabecular thickness, the acquisition time (acq. Time), and the SNR (>10) being clinically compatible. On that basis, 7T MR scanners have been tested mostly for the acquisition of distal and proximal femur, which represent a clinical important fracture site and one of the most invalidating [8].

In a comparative study conducted in vivo in proximal femur at 1.5 and 3T, Krug et al., reported as expected a 1.6 time-SNR increase together with a corresponding contrast-tonoise ratio (CNR) increase at higher magnetic field. While the 3T images clearly showed the trabecular bone structure, the image resolution did not allow a proper trabecular morphological analysis [71]. In a more recent study in the knee joint of 16 healthy volunteers scanned at $1.5 \mathrm{~T}(0.6 \mathrm{~mm} \times 0.6 \mathrm{~mm} \times 0.6 \mathrm{~mm}$, acq. time 7:15 $\mathrm{min})$ and $3 \mathrm{~T}$ $(0.5 \mathrm{~mm} \times 0.5 \mathrm{~mm} \times 0.5 \mathrm{~mm}$, acq. time 6:51 $\mathrm{min})$, Abdulaal et al. reported significantly higher SNR $(p<0.05)$ allowing a better trabecular characterization at 3T than 1.5T [112]. Moreover, 3T MRI could be used to successfully scan radii with an in-plane pixel size comparable to the trabecular thickness and an acquisition time (10 $\mathrm{min})$ lower than what commonly needed at $1.5 \mathrm{~T}[101,113]$. Jarraya et al., on a study conducted in 50 distal radii scanned at both $3 \mathrm{~T}(0.2 \mathrm{~mm} \times 0.2 \mathrm{~mm} \times 2.0 \mathrm{~mm}$, acq. time 4:29 $\mathrm{min})$ and 7T MR $(0.125 \mathrm{~mm} \times 0.125 \mathrm{~mm} \times 2.0 \mathrm{~mm}$, acq. time 3:16 $\mathrm{min})$, reported a statistical significant difference of horizontal and fractal dimensions between patients with chronic wrist disease and controls [114]. A similar comparative analysis has been performed between 3T and 7T MRI $(0.156 \mathrm{~mm} \times 0.156 \mathrm{~mm} \times 0.5 \mathrm{~mm}$, acq. time lower than $10 \mathrm{~min})$ and HR-pQCT. Krug et al. showed that tibial trabecular structures were over-represented at higher field strength. Due to susceptibility-induced broadening smaller trabeculae normally not visible due to partial volume effects may be emphasized at 7T [88]. Moreover, using UHF MRI $(0.234 \mathrm{~mm} \times 0.234 \mathrm{~mm} \times 1.0 \mathrm{~mm}$, acq. time $7 \mathrm{~min})$, Chang et al. reported that microarchitectural parameters could discriminate between patients and controls and could detect bone deterioration in women with fragility fractures for whom BMD was normal [18]. In 
addition to the effects of magnetic field strength, Krug et al. also assessed the potential differences between GRE and TSE sequences at 7T. SNR was slightly higher for GRE sequences (13.2 vs. 11.9) while the bone marrow signal was more homogeneous using TSE sequences. This large homogeneity is related to a reduced susceptibility-induced broadening of the trabeculae so that the morphological analysis showed decreased BVF $(-13 \%)$ and Tb.Th $(-23 \%)$. These values were closer to those reported using the HR-pQCT reference method [88]. Furthermore, in a study conducted in three cadaveric proximal femurs scanned at 7T $(0.130 \mathrm{~mm} \times 0.130 \mathrm{~mm} \times 1.5 \mathrm{~mm}$, acq. time $16 \mathrm{~min})$ and using $\mu \mathrm{CT}$, Soldati et al. reported no statistical difference between the methods and so for the whole set of morphological parameters [81]. These preliminary results strongly suggest that UHF MRI could be of interest for the in vivo assessment of bone microarchitecture particularly for the deep anatomical regions.

\subsection{Comparison with CT Measurements}

Validation of the bone morphological parameters derived from the high-resolution MR images has usually been performed through the comparison with $\mathrm{X}$-ray based techniques (qCT, HRpQCT, and $\mu \mathrm{CT}$ ).

\subsubsection{Ex-Vivo}

Ex vivo studies have been performed in different body parts. However, due to the samples size $\left(<5 \mathrm{~cm}^{3}\right)$ and the commonly used preparation protocols (replacement of marrow), they remain poorly representative of the in vivo conditions [13,78,81,102,115]. One of the first studies validating MR bone structure measurements was performed by Hipp et al. in cubic bovine trabecular bone from several anatomical sites using optical and micro-MRI methods. BVF and Tb.N were linearly related $\left(r^{2}=0.81\right.$ and $r^{2}=0.53$ respectively) and did not differ statistically $(p=0.96$ and $p=0.17)[78,115]$. These results were confirmed and extended in human specimens by Majumdar et al., in a study conducted in 7 cubic specimens of trabecular bone extracted from cadaveric radii scanned at $1.5 \mathrm{~T}$ $(0.156 \mathrm{~mm} \times 0.156 \mathrm{~mm} \times 0.3 \mathrm{~mm})$ and using $\mu \mathrm{CT}(0.018 \mathrm{~mm}$ isovolumetric $)$. The results showed a good correlation for the whole set of metrics with BVF and Tb.Th performing the best $(r=0.77$ and 0.87 respectively) and Tb.Sp and Tb.N the worst $(r=0.53$ and 0.6 respectively). However a significative statistical difference $(p>0.01)$ was reported for all the calculated features [13]. MRI images with an in plane pixel-size lower than the smallest trabecular thickness order $(0.1 \mathrm{~mm})$ are not easily reachable. On that basis, one cannot expect to fully characterize it. Moreover, these findings were further extended in a larger study conducted in 39 distal radius specimens scanned at 1.5T MRI $(0.152 \mathrm{~mm} \times 0.152 \mathrm{~mm} \times 0.9 \mathrm{~mm})$ and using contact radiography $(0.05 \mathrm{~mm}$ isovolumetric $)$. The results showed a significant correlation $(\mathrm{r}>0.61)$ between bone microstructure parameters derived from both methods with Tb.Sp and BVF providing the highest correlations ( $\mathrm{r}=0.69$ and $p=0.75$ respectively) [102]. More recently, Rajakapse et al. conducted a study in 13 cylindrical specimens (7 proximal femurs, 3 proximal tibiae, and 3 third lumbar vertebrae) extracted from 7 human donors and computed microarchitectural parameters using 9.4T micro-MRI ( $0.050 \mathrm{~mm}$ isovolumetric) and $\mu \mathrm{CT}$ (0.021 mm isovolumetric). Architectural parameters were found to highly correlate between these two modalities with a slope close to unity ( $\mathrm{r}^{2}$ ranging from 0.78 to 0.97 ) [116]. In a more recent study conducted in three cadaveric entire proximal femurs evaluating the trabecular morphology using 7T MRI $(0.13 \mathrm{~mm} \times 0.13 \mathrm{~mm} \times 1.5 \mathrm{~mm})$ and comparing the results with those acquired using $\mu \mathrm{CT}$ (0.051 mm isovolumetric) (Figure 1), Soldati et al. showed a good intraclass correlation coefficient for all the parameters (ICC > 0.54) between 7T and $\mu \mathrm{CT}$ [81] illustrating that bone morphological metrics of human specimens can be properly assessed using MRI. Moreover, due to the comparison between MR images and gold standard high-resolution CT images, it has been shown that trabecular features derived from images with a similar pixel size provide statistically comparable results. However, when assessing bone trabecu- 
lae using MRI, partial volume effects will occur and will affect image segmentation and trabeculae quantification.

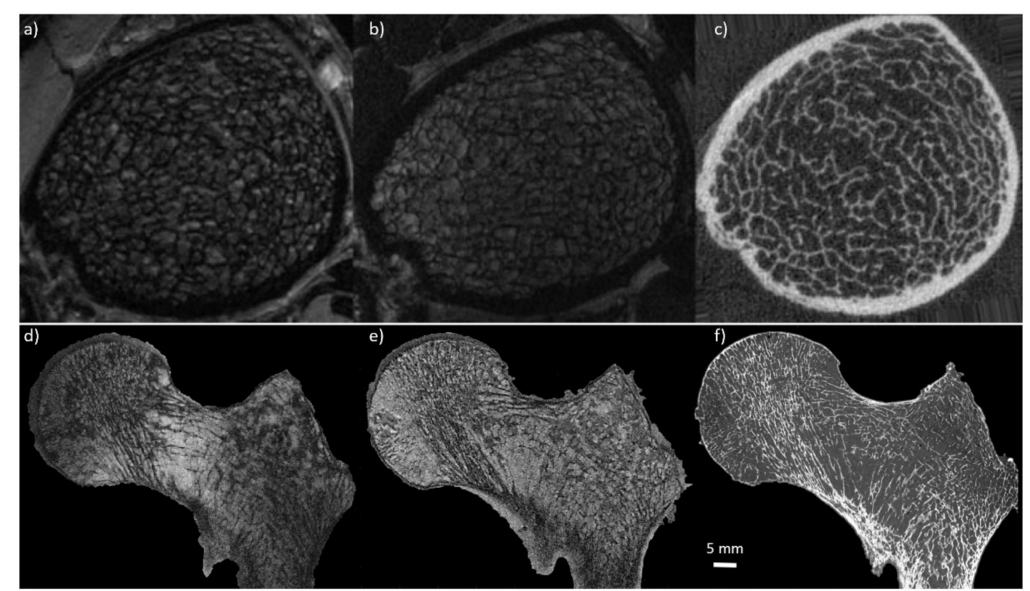

Figure 1. Comparison between MRI and CT. (first row) MR images of in vivo distal tibia acquired using gradient echo sequence at 7T MRI (a) $(0.156 \mathrm{~mm} \times 0.156 \mathrm{~mm} \times 0.5 \mathrm{~mm})$ and $3 \mathrm{~T}$ MRI (b) $(0.156 \mathrm{~mm} \times 0.156 \mathrm{~mm} \times 0.5 \mathrm{~mm})$, and compared with high-resolution peripheral computed tomography (HR-pQCT) (c) $\left(0.082 \mathrm{~mm}^{3}\right)$ (reproduced from J. of Mag. Res. Im. 27:854-859 (2008)). (second row) MR images of cadaveric proximal femur acquired using turbo spin echo sequence at 7T MRI (d) $(0.13 \mathrm{~mm} \times 0.13 \mathrm{~mm} \times 1.5 \mathrm{~mm})$ and 3 T MRI (e) $(0.21 \mathrm{~mm} \times 0.21 \mathrm{~mm} \times 1.1 \mathrm{~mm})$, and compared with $\mu \mathrm{CT}(\mathbf{f})\left(0.051 \mathrm{~mm}^{3}\right)$. Note that using MRI, the trabecular bone appears black and bone marrow delivers the bright signal whereas for HR-pQCT and $\mu \mathrm{CT}$ the trabecular bone is shown bright. Additionally, note that the trabecular network is clearly more enhanced at 7T compared to 3T.

\subsubsection{In-Vivo}

The MRI potential for the bone microstructure has also been assessed in vivo in anatomical regions more affected by osteoporosis, i.e., tibiae and radii, vertebrae [65,117,118], distal $[18,108,109,111,119]$, and proximal femurs [60,71,72]. Microarchitectural parameters extrapolated from 3T MRI $(0.156 \mathrm{~mm} \times 0.156 \mathrm{~mm} \times 0.5 \mathrm{~mm})$ and compared to HR-pQCT of tibiae and radii of 11 healthy volunteers showed good correlation for BVF $(r=0.83)$ and Tb.Sp $(r=0.7)$ in tibiae and good correlation for all the microarchitecture parameters investigated in radii $(\mathrm{r}=0.65,0.95,0.83$, and 0.63 for BVF, Tb.N, Tb.Sp, and Tb.Th respectively) [77]. Kazakia et al. extended these results in a study conducted in tibiae and radii of 52 postmenopausal scanned at 3T MRI $(0.156 \mathrm{~mm} \times 0.156 \mathrm{~mm} \times 0.5 \mathrm{~mm})$ and using HR-pQCT. A significant correlation between MRI and HR-pQCT has been reported for Tb.N ( $\left.\mathrm{r}^{2}=0.52\right)$ and Tb.Sp $\left(\mathrm{r}^{2}=0.54-0.60\right)$ with no statistical difference for these two parameters. Poor correlations were reported for BVF and Tb.Th $\left(r^{2}=0.18-0.34\right)$ [120]. Similar results were also reported by Folkesson et al., in a study conducted in 52 postmenopausal women scanned at $3 \mathrm{~T}(0.156 \mathrm{~mm} \times 0.156 \mathrm{~mm} \times 0.5 \mathrm{~mm})$ and using HR-pQCT in both tibiae and radii. All the structural parameters derived from MRI were highly correlated to those obtained from HR-pQCT (Tb.N was equal to 0.68 and 0.73 and Tb.Sp was equal to 0.77 and 0.67 for tibiae and radii respectively) with the exception of BVF and $\mathrm{Tb}$. Th for which correlations were less significant (BVF was equal to 0.61 and 0.39 and $\mathrm{Tb}$.Th was equal to 0.43 and 0.32 for tibiae and radii respectively) [113]. Furthermore, Krug et al. confirmed and extended these results in a study conducted in distal tibiae of 10 healthy volunteers scanned at 3T and 7T $(0.156 \mathrm{~mm} \times 0.156 \mathrm{~mm} \times 0.5 \mathrm{~mm}$ for both techniques $)$. The results showed that microarchitectural parameters extracted from HR-pQCT images had higher correlation with those extracted from 7T MR images (r equal to 0.73 for BVF, 0.69 for Tb.N, 0.89 for Tb.Sp, and 0.13 for Tb.Th) as compared to 3T MR images ( $\mathrm{r}=0.83$, $0.49,0.67$, and 0.15 for BVF, Tb.N, Tb.Sp, and Tb.N respectively) (Figure 1). Interestingly, the corresponding absolute values did only differ by $0.6 \%$ for $7 \mathrm{~T}$ and $3 \%$ for 3T [88]. All the findings reported above indicate good correlations for Tb.Sp and Tb.N between MRI and 
HR-pQCT. In contrast, this was not the case for BVF and Tb.Th. The limited resolution in MRI leads to partial volume effects responsible for the exclusion of the smallest trabeculae, while susceptibility artifacts enhance the remaining trabeculae leading to an overestimation of Tb.Th. This double effect seems limited when using UHF MRI. Indeed, good correlations were found between MRI and HR-pQCT metrics although a poor correlation was still existing for $\mathrm{Tb}$.Th.

\subsection{Reported Limitations}

The main limitation reported regarding the bone morphology evaluation using MRI is related to partial volume effects resulting from the ratio between the resolution offered by the MR machines and the trabecular dimension. The minimum trabecular size is in the order of $0.1 \mathrm{~mm}$. If the pixel size is larger than this limit, trabecular broadening would occur. In the worst possible scenario, trabecular broadening would cause the disappearance or the aggregation of the finest trabeculae leading to over- or underestimation of the main morphological characteristics [13,62,81,88,116]. Majumdar et al. reported an overestimation of the BVF ( 3 times) and the Tb.Th ( 3 times) and an underestimation of the Tb.Sp (1.6 times) in the MR images $(0.156 \mathrm{~mm} \times 0.156 \mathrm{~mm} \times 0.3 \mathrm{~mm})$ compared to the 18- $\mu \mathrm{m} \mu \mathrm{CT}$ images [13]. Many studies conducted in different anatomical sites both in vivo and in vitro have shown that increasing the main magnetic field strength may emphasize small trabecular structures, normally not visible due to partial volume effects and susceptibility-induced broadening $[81,88]$. Moreover, several studies have shown that spin echo sequence are less prone to partial volume effects than gradient echo ones [77,88,100]. In particular, Krug et al. compared gradient echo and spin echo sequences at 7T and the results showed that SE sequence provided decreased BVF $(-13 \%)$ and $\mathrm{Tb}$.Th $(-23 \%)$ and an increase in Tb.N (13\%) and Tb.Sp (1\%) as compared to gradient echo [88]. SE sequences have shown their higher discriminative power to resolve the bone microstructure due to a more homogeneous bone marrow signal. However, at UHF spin-echo sequences should be used carefully due to a specific absorption rate (SAR) that limits the number of acquirable images. Soldati et al. reported a maximum number of 10 acquired images using a turbo spin echo sequence at 7T in approximately $16 \mathrm{~min}$.

MR imaging conducted in cadaveric specimens may suffer from an additional limitation related to air bubbles trapped in the trabecular network and leading to magnetic susceptibility effects [81,116]. Air bubbles provide grey level intensities similar to the bone signal so that pixel misclassification could be expected. In order to properly perform MRI acquisition of cadaveric specimens air bubbles have to be removed using different strategies that have been reported and validated through images analysis $[81,107,116]$. The common strategy used mainly for small specimens $\left(<5 \mathrm{~cm}^{3}\right)$ is related to the bone marrow removal through a gentle water jet, the immersion in $1 \mathrm{mM}$ Gd-DTPA saline solution to simulate the bone marrow magnetic response and the removal of air bubbles using centrifugation (approximately between $5 \times$ to $6 \times g$, for $5 \mathrm{~min}$ ) $[13,107,116]$. Hipp et al. reported an alternative solution consisting in filling marrow spaces with confectioners' sugar to provide contrast between bone and marrow [78]. More recently, Soldati et al. reported no trabecular misclassification due to air bubbles by combining vacuum application and vibrational forces to large cadaveric specimens (entire proximal femurs) immersed in $1 \mathrm{mM}$ Gd-DTPA saline solution [81].

\section{Prospectives}

In this chapter we provide an overview of the most recent results reported in the literature, which are related to the assessment of bone marrow using magnetic resonance spectroscopy and chemical shift encoding MRI, bone phosphorus content, and bone mineral density using solid-state MRI and quantitative susceptibility measurements. These techniques are considered promising to further investigate bone quality. 


\subsection{Magnetic Resnance Spectroscopy vs. Chemical Shift Encoding-MRI}

Several MRI studies have shown that bone marrow, which is mainly composed by adipocytes (yellow marrow regions) and hematopoietic red blood cells (red marrow regions), may play a key role in the bone health and metabolism. Moreover, it has been reported that distinct alterations become increasingly evident when comparing osteoporotic subjects to controls $[121,122]$. The bone marrow fat content can be assessed from bone marrow fat fraction (BMFF) and proton density fat fraction (PDFF) measurements [122,123]. Bone marrow has been actually investigated using magnetic resonance spectroscopy (MRS) and chemical shift encoding based water fat MRI (CSE-MRI).

Up to now, the most frequently used technique for bone marrow quantification has been the single-voxel proton MRS, which is also considered the gold-standard. Based on a localized scheme, water and fat components can be quantified on the basis of their respective resonance frequencies. Point-resolved spectroscopy (PRESS) and stimulated echo acquisition mode (STEAM) have been mainly used. Given that the STEAM sequence allows shorter TEs as compared to PRESS, a higher signal can be expected for the short-T2 water component of the BM spectrum [122].

MRS has been used to assess BMFF at the spine level [31,33,37,124-127] and fewer studies have been devoted to the proximal femur [128-130]. Correlations between BMFF and BMD or T-scores have been repeatedly reported. BMFF is elevated in osteoporotic patients and negative correlations have been reported between BMFF and BMD. He et al., in a study conducted in L2-L4 vertebrae of 123 subjects ( 49 with normal bone density, 38 with osteopenia and 36 with osteoporosis) scanned using PRESS at 3T (voxel size $15 \times 15 \times 15 \mathrm{~mm}^{3}$ ) showed that BMFF was increased in patients with reduced BMD values while the metrics were negatively correlated $(\mathrm{r}=-0.82, p<0.001)$ [125], further confirming previous results on the lumbar spine (L1-L2) and proximal femurs [131]. In a study conducted in femoral neck of 33 postmenopausal woman using 3T MRS (PRESS sequence, single voxel $15 \times 15 \times 15 \mathrm{~mm}^{3}$ ), Di Pietro et al. reported larger content of methylene (L13), glycerol (L41,L43), and total lipid in osteoporotic subjects [129]. There changes suggest that MRS of bone marrow lipid profiles from peripheral skeletal sites might be a promising screening tool to identify individuals with or at risk of developing osteoporosis $[129,132]$.

CSE-MRI can be used to obtain a spatially resolved quantification of BMFF. Multiecho GRE sequences are commonly used with an appropriate selection of experimental parameters (i.e., small flip angle to reduce $\mathrm{T} 1$ bias, and distinct correction of $\mathrm{T} 2$ * decay effects during the postprocessing stage) $[122,126,133,134] . T 2 *$ decay effects have to be particularly considered when measuring the PDFF. In fact, T2* of trabecular bone is reduced due to microscopic magnetic field inhomogeneity effects [122].

A good agreement has been reported between BMFF measured using MRS and CSEMRI for both spine and proximal femur [135-137]. At the spine level, BMFF has been reported as increased in osteoporotic patients and inversely correlated with BMD and Tscores $[122,135,138]$. At the proximal femur level, Martel et al., reported a higher saturation $(+14.7 \%$ to $+43.3 \%)$, and a lower mono- $(-11.4 \%$ to $-33 \%)$ and polyunsaturation $(-52 \%$ to $-83 \%$ ) in postmenopausal women. More specifically, red marrow of postmenopausal women showed a lower fat content $(-16 \%$ to $-24 \%)$ and a decreased polyunsaturation $(-80 \%$ to $-120 \%)$ in the femoral neck, greater trochanter, and Ward's triangle [139]. In another study, it has been reported that PDFF derived from CSE-MRI would discriminate benign osteoporotic and malignant vertebral fractures. Accordingly, Schmeel et al. reported that both PDFF and PDFF ratio (fracture PDFF/normal vertebrae PDFF) of malignant VCFs were significantly lower as compared to acute benign (PDFF, $3.48 \pm 3.30 \%$ vs. $23.99 \pm 11.86 \%(p<0.001)$ and $\mathrm{PDFF}_{\text {ratio }}, 0.09 \pm 0.09$ vs. $\left.0.49 \pm 0.24(p<0.001)\right)$. The corresponding areas under the curve were 0.98 and 0.97 for PDFF and $\mathrm{PDFF}_{\text {ratio }}$ respectively providing a $96 \%$ and $95 \%$ accuracy for the discrimination between acute benign and malignant VCFs [140]. CSE-MRI conducted in 156 subjects at 3T (8 echoes 3D spoiled gradient echo sequence, voxel size $0.98 \mathrm{~mm} \times 0.98 \mathrm{~mm} \times 4.00 \mathrm{~mm}$, acq. time 1:17 $\mathrm{min}$ ), showed that vertebral bone marrow heterogeneity is primarily dependent on sex and age 
but not on anatomical location suggesting that future studies should investigate the bone marrow heterogeneity with regards to aging and disease [141]. Baum et al. in a study conducted on the whole spine of 28 young and healthy patients using CSE-MRI at 3T (8 echoes, acq. time 3:15 min), extend these results reporting that the repeatability of PDFF measurements expressed an averaged absolute precision error of 1.7\% over C3-L5 [142].

MRS and CSE-MRI have enabled the evaluation of the nonmineralized bone compartment and the extraction of the PDFF. The marrow adipose tissue has shown to have a role in bone health, through its paracrine and endocrine interaction with the other bone components. However, the implication of marrow adipose tissue in physiological and pathological conditions remains unclear [143].

\subsection{MR Susceptibility}

Magnetic susceptibility is the macroscopic physical quantity that describes the tissue's induced magnetization in the presence of an external magnetic field. Since the early days of MRI, susceptibility quantification has been considered as of paramount interest given that it is related to the tissue's chemical composition. Even a small susceptibility change can lead to field distortions that could be quantified. This has been achieved through SWI (susceptibility weighted imaging) $[144,145]$ and quantitative aspects could be computed from MRI phase and magnitude signals by means of QSM (quantitative susceptibility mapping) [146,147].

Dense calcified tissues, such as bone, show a strong diamagnetic behavior. On that basis, QSM [148] could be used to assess bone mineral changes [149]. Although QSM has been largely developed for brain imaging $[150,151]$, the corresponding applications for bone are still considered very challenging. Cortical bone has a very low signal using conventional echo times GRE imaging and water connected to the crystalline mineral structures or to the collagen matrix has an ultrashort transverse relaxation time (T2 * $=300 \mu \mathrm{s}$ [152]) thereby showing a non-meaningful signal for QSM. In order to overcome this issue, ultrashort echo-time (UTE) GRE imaging [148] has been developed to obtain phase information for reliable QSM, which may be used in the evaluation of BMD [153].

For example, correlations between QSM and BMD have been studied through clinical MRI sequences in spine and ankle trabecular bones [153,154]. In Chen et al. [153], the efficacy of QSM in the assessment of osteoporosis for post-menopausal women was investigated. The L3 vertebrae body of 70 post-menopausal women was studied through a multi-GRE UTE sequence on a 3T MR system $(\mathrm{TR}=20 \mathrm{~ms}$, TE $=0.142,2.4,4.6$, and $6.8 \mathrm{~ms}$, voxel size $=1.0 \mathrm{~mm} \times 1.0 \mathrm{~mm} \times 2.0 \mathrm{~mm}$, and acq. time $=10 \mathrm{~min}$ ) and a qCT examination. Based on qCT values, individuals were divided into normal and affected by osteopenia or osteoporosis. The QSM values were higher for the osteoporosis group than in either the normal or the osteopenia group $(p<0.001)$ and showed an highly negative correlation with qCT values $(r=-0.72, p<0.001)$ [153].

Non-UTE multi-GRE sequences can be applied to QSM: ankle in vivo imaging was performed by Diefenbach et al. using a time-interleaved gradient-echo sequence (TIM-GRE) at $3 \mathrm{~T}\left(9\right.$ echoes, $\mathrm{TE}_{\min }=1.25 \mathrm{~ms}$ with $\Delta \mathrm{TE}=0.7 \mathrm{~ms}$, voxel size $=1.5 \mathrm{~mm} \times 1.5 \mathrm{~mm} \times 1.5 \mathrm{~mm}$, and acq. time $=7 \mathrm{~min}$ ) in order to evaluate the feasibility of QSM for trabecular bone imaging and investigate its sensitivity for measuring trabecular bone density [154]. Mean susceptibility values in calcaneus regions with different trabecular bone density were compared to CT attenuation values. In highly trabecularized regions, qCT values showed significant correlation with lower susceptibility values $(\mathrm{r}=-0.8, p=0.001)$ [154]. In addition, differences in calcaneus trabecularization were outlined in QSM maps in good agreement with qCT and high resolution MR images.

Furthermore, cones 3D UTE-MRI techniques have recently been developed showing similar susceptibility values but faster scanning process if compared with other different sampling strategies [155]. In Jerban et al. [156], cones 3D UTE-MRI was implemented for ex vivo QSM in order to investigate correlations of susceptibility with volumetric intracortical BMD in human tibial cortical bone. Nine tibial midshaft cortical bones specimens were 
scanned in a 3T clinical scanner with a cones 3D UTE-MRI sequence for QSM (TE $=0.032$, $0.2,0.4,1.2,1.8$, and $2.4 \mathrm{~ms}$, voxel size $=0.5 \mathrm{~mm} \times 0.5 \mathrm{~mm} \times 2.0 \mathrm{~mm}$, and acq. time $=20 \mathrm{~min})$ and with high-resolution $\mu \mathrm{CT}$ for BMD estimation (Figure 2). Average QSM values were calculated in one slice ( $2 \mathrm{~mm}$ thickness) at the middle of the specimen and showed a strong correlation with volumetric BMD $(\mathrm{r}=-0.82, p=0.01)$ and bone porosity $(\mathrm{r}=0.72, p=0.01)$. Results in this study highlight the potential of 3D cones UTE-MRI QSM as a possible future tool in the in vivo diagnosis of bone diseases that can be detected through mineral level variations in cortical bone.

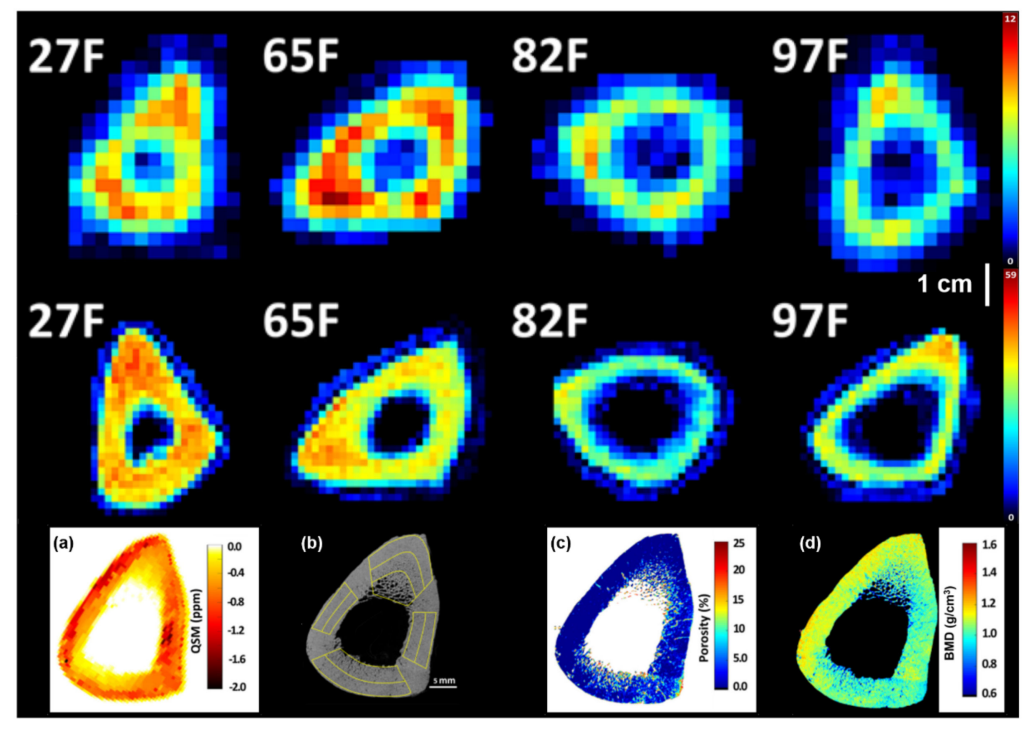

Figure 2. Solid state MRI and quantitative susceptibility mapping. (first row) Maps of bone mineral ${ }^{31} \mathrm{P}$ density, and bound water density (second row) in central slices of 4 human tibial cortical bone specimens. Age and gender of bone specimen donors are indicated. Bone mineral ${ }^{31} \mathrm{P}$ and bound water ${ }^{1} \mathrm{H}$ densities are markedly lower in bones from elderly female donors than from younger females or males. ${ }^{31} \mathrm{P}$ maps also suffer from increased point spread function blurring because of the lower gyromagnetic ratio and shorter T2 * of ${ }^{31} \mathrm{P}$. (reproduced from NMR Biomed. 27: 739-748 (2014)) (third row) (a) QSM map obtained through Cones 3D UTE-MRI scans ( $0.5 \mathrm{~mm} \times 0.5 \mathrm{~mm} \times 2 \mathrm{~mm}$ voxel size) of a tibial midshaft cortical bone (45-year-old female), (b) one $\mu \mathrm{CT}$ slice at $9 \mu \mathrm{m}$ isotropic voxel size, (c) $\mu$ CT-based porosity, and (d) BMD map of the same specimen. Local maxima in the QSM map correspond to high BMD regions and low porosity values in $\mu$ CT-based maps (reproduced from Magn. Res. Im. 62: 104-110 (2019)).

Despite its potential in providing an X-ray radiation free approach to quantify susceptibility in bone tissue, QSM suffers from some limitations. Data processing is relatively complex and still under study while data acquisition times are too long if compared to clinical MRI sequences. Furthermore, bone susceptibility variations due to soft surrounding tissues should be taken into account in future in vivo clinical studies and applications.

\subsection{Solid State MRI}

Solid state MRI has been recently described in a review by Seifert and Wehrli [157]. One of the main issued faced by MRI of the solid part of bones is the extremely weak MR signal. In order to acquire the fast decaying (i.e., short T2 ${ }^{*}{ }^{1} \mathrm{H}$ and ${ }^{31} \mathrm{P}$ MRI signals in bone, the time between signal excitation, encoding, and acquisition must be shorter than the one used in conventional MRI sequences $[157,158]$. Hence, to image short-T2* tissues three solid state radial pulse sequences have emerged: ultrashort echo time (UTE) [159], zero echo time (ZTE) $[160,161]$, and sweep imaging with Fourier transformation (SWIFT) [162-164]. The main strategy to image short-T2 * tissue is to reduce the time delay between the end of the signal excitation and the beginning of encoding and acquisition. In UTE, the time delay is reduced by beginning the signal encoding and acquisition simultaneously and immediately 
after the MRI system's transmit/receive switching dead time has elapsed [159,165]. In ZTE, signal encoding is begun simultaneously with the excitation, but the time delay to signal acquisition is still dictated by the transmit/receive dead time resulting in the loss of the first data points in the acquisition [166-168]. In SWIFT, the three steps (excitation, encoding, and acquisition) are performed in a finely interleaved (gapped) [162] of fully simultaneous (continuous) [163] manner, allowing the in vivo imaging of teeth, where the $\mathrm{T} 2 *$ is even shorter than that of bone [169]. All these sequences have been used ex vivo and in vivo applying whole-body MRI scanners at different field strengths. However, in the case of in vivo solid-state NMR of tibial shafts, a minimum voxel size of $0.98 \mathrm{~mm}^{3}$ for ${ }^{1} \mathrm{H}$ and $2.5 \mathrm{~mm}^{3}$ for ${ }^{31} \mathrm{P}$ is required to have enough SNR at an acceptable acquisition time $\left(<10 \mathrm{~min}\right.$ for ${ }^{1} \mathrm{H}$ and $<25 \mathrm{~min}$ for $\left.{ }^{31} \mathrm{P}\right)$ and to avoid SAR limitation $[157,170]$.

Solid-state MRI could be used to compute total bone water (TW), water bound to the collagen matrix $(\mathrm{BW})$, and pore water (PW). Several consistent studies from different groups have been reported for bone extremities [63,170-173] showing also the ability to differentiate between pre- and post-menopausal women. Techawiboonwong et al., in a study conducted in distal tibiae of pre-menopausal and post-menopausal women $(n=5$ for each group) scanned using an UTE sequence at 3T MRI (pixel size $0.3 \mathrm{~mm} \times 0.3 \mathrm{~mm} \times 8.0 \mathrm{~mm}$ and acq. time $=9 \mathrm{~min}$ ) reported a difference in the TW concentration of $17.4 \%$ and $28.7 \%$ respectively for the pre- and post-menopausal groups [171]. Moreover, BW and PW were acquired in vivo tibiae and wrist of 5 volunteers using 3T MR scanner (isotropic pixel size of $1.5 \mathrm{~mm}$ in the leg and 1.2 in the wrist and acq. time $=8-14 \mathrm{~min}$ per acquisition) reporting a mean BW of $34.86 \pm 2.59 \mathrm{M}$ and a mean PW $6.14 \pm 1.97 \mathrm{M}$, similar to previously ex vivo observations [172-174].

Using ${ }^{31} \mathrm{P}$ NMR, solid-state MRI could also be used to quantitatively assess the mass of bone mineral in bone tissue [175]. An ex vivo study conducted in 16 tibiae specimens acquired using ZTE ${ }^{31} \mathrm{P}$ at 7T (pixel size $=3.84 \mathrm{~mm}$ isovolumetric and acq. time $=3 \mathrm{~h}$ and $3 \mathrm{~min}$ ) and ${ }^{1} \mathrm{H}$ at $3 \mathrm{~T}$ (pixel size $=1.17 \mathrm{~mm}$ isovolumetric and acq. time $=26 \mathrm{~min}$ and $45 \mathrm{~s}$ ) by Seifert et al. (Figure 2), reported a mean bone mineral ${ }^{31} \mathrm{P}$ density of $6.74 \pm 1.22 \mathrm{M}$ and mean $\mathrm{BW}{ }^{1} \mathrm{H}$ density of $31.3 \pm 4.2 \mathrm{M}$ [14]. In addition, ${ }^{31} \mathrm{P}$ and $\mathrm{BW}$ densities correlated positively with pQCT density ( ${ }^{31} \mathrm{P}: \mathrm{r}^{2}=0.46, p<0.05$; BW: $\mathrm{r}^{2}=0.50$, and $\left.p<0.005\right)$, showing that MRI-based measurements are able to detect intersubject variations in apparent mineral and osteoid density in human cortical bone using clinical hardware [14,176]. However, Tamimi et al. in a study conducted on trabecular femur head samples collected from patients who had hip fractures and individuals with osteoarthritis reported no differences in neither ${ }^{1} \mathrm{H}$ nor ${ }^{31} \mathrm{P}$ between the two groups [177].

In a more recent study performed on in vivo tibiae of 10 healthy subjects, Zhao et al. acquired at $3 \mathrm{~T}{ }^{1} \mathrm{H}$ UTE (pixel size $=0.98 \mathrm{~mm}^{3}$ and acq. time $=8: 20 \mathrm{~min}$ ) and ${ }^{31} \mathrm{P}$ ZTE (pixel size $=2.5 \mathrm{~mm}^{3}$ and acq. time $=22: 30 \mathrm{~min}$ ). They showed no differences in the ${ }^{31} \mathrm{P}$ concentration in healthy adults across 50-years of age [178] and a strong positive correlation $(\mathrm{r}=0.98, p<0.0001)$ between bone mineral content (BMC) measured using ${ }^{31} \mathrm{P} \mathrm{MRI}$ and HR-pQCT [170], further extending previous in vivo studies [179].

Therefore, solid-state MRI has shown its potential as translational techniques into clinical research and practice providing information related to the mineral composition of bone tissue, bound, and pore water. However spatial resolution, SNR, and scan time remain key challenges for the solid state MRI $[157,170,180]$. These three characteristics are dependent on each other and a trade-off has to be established to retrieve useful information in a clinically acceptable acquisition time. Usually, a SNR higher or equal to 10 is recommended and, to maintain the acquisition time in an acceptable range, the voxel size is enlarged along the bone axis where features are considered to be constant.

\section{Conclusions}

Over the last decades, the multiple technical improvements that have been made in MRI have opened new MRI applications such as a bone microarchitecture assessment. Up to now, most of the MRI studies conducted in bones have been performed using $1.5 \mathrm{~T}$ and 
3T scanners. However, results obtained at UHF showed the technical advantages and the higher discriminative power of 7T MRI for the assessment of the bone microstructure of the most proximal anatomic locations, including those more affected by osteoporotic fractures. The advantages provided by UHF MRI have shown great potential on the bone microstructure assessment and made this technique almost ready for a daily clinical application.

Moreover, bone morphological parameters derived from both specimens and patients acquired using MRI were shown to provide features in the same range of those derived with the gold-standard X-rays techniques, with the great advantage of being completely non-invasive for the patients. In addition, MRI was also shown to be able to provide supplementary information about the mineral content, i.e., phosphorous density, not accessible using X-rays techniques. Furthermore, MRI microarchitecture analysis was able to evaluate changes related to age and/or pathology suggesting the great clinical potential for MRI in evaluating different bone pathologies, assessing the risk stratification, and following the therapy delivery.

Up to now, BMD derived from DXA measurements was the only parameter used to identify bone related pathologies. Several studies have demonstrated that microarchitectural parameters provide additional information regarding the skeletal fragility and should be integrated with BMD to provide a more comprehensive view of the bone quality. MRI is completely radiation free and the application of UHF MRI made accessible the anatomical regions further away from the skin surface, with a resolution in the same range of trabecular thickness, and in an acquisition time compatible for in vivo clinical use. Moreover, MRI, and in particular UHF MRI, showed to provide bone morphological parameters in the same range of gold standard analysis both in specimens and patients.

Finally, MSC and CSE-MRI, solid state MRI, and QSM have shown to be useable in in vivo acquisitions providing bone marrow fat quantification, mineral composition of bone tissue, bound, and pore water, and magnetic susceptibility quantification. However, for the clinical application of solid state MRI and QSM acquisition times would have to be reduced. MRI could certainly be added to BMD measurements for a complete analysis of bone quality, health, and metabolism.

Author Contributions: Conceptualization, E.S., M.P., S.I., E.M. and D.B.; methodology, E.S. and F.R.; validation, D.G., M.P. and D.B.; formal analysis, E.S., J.V. and E.M.; investigation, E.S. and F.R.; data curation, E.S., F.R., J.V. and E.M.; writing-original draft preparation, E.S., and F.R.; writing-review and editing, E.S., F.R., M.P., J.V., S.I., E.M. and D.B.; supervision, M.P., J.V., S.I., E.M. and D.B.; project administration, D.B.; funding acquisition, D.B. All authors have read and agreed to the published version of the manuscript.

Funding: E.S. has received funding from the European Union's Horizon 2020 research and innovation program under the Marie Skodowska-Curie grant agreement No713750. Additionally, it has been carried out with the financial support of the Regional Council of Provence Alpes-Côte $d^{\prime}$ Azur and with the financial support of the A*MIDEX ( ${ }^{\circ}$ ANR-11-IDEX-0001-02), funded by the "Investissements d'Avenir" project funded by the French Government, managed by the French National Research Agency (ANR). No authors is affiliated to an Intergovernmental Organization.

Institutional Review Board Statement: Not appliable.

Informed Consent Statement: Not appliable.

Data Availability Statement: No new data were created or analyzed in this study. Data sharing is not applicable to this article.

Conflicts of Interest: The authors declare no conflict of interest. The funders had no role in the design of the study; in the collection, analyses, or interpretation of data; in the writing of the manuscript, or in the decision to publish the results. 


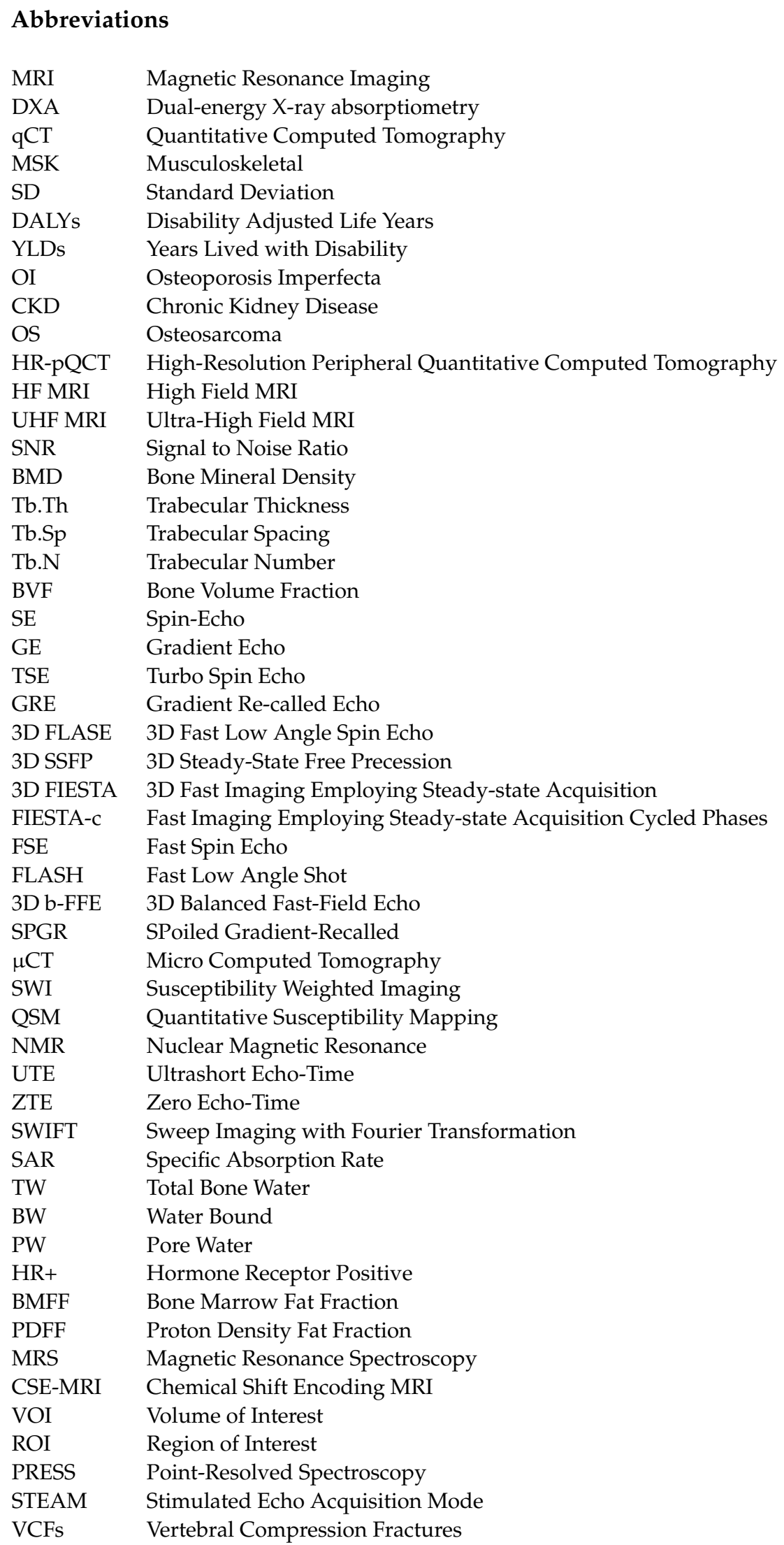




\section{References}

1. Vos, T.; Flaxman, A.D.; Naghavi, M.; Lozano, R.; Michaud, C.; Ezzati, M.; Shibuya, K.; Salomon, J.A.; Abdalla, S.; Aboyans, V.; et al. Years Lived with Disability (YLDs) for 1160 Sequelae of 289 Diseases and Injuries 1990-2010: A Systematic Analysis for the Global Burden of Disease Study 2010. Lancet 2012, 380, 2163-2196. [CrossRef]

2. Lim, S.S.; Vos, T.; Flaxman, A.D.; Danaei, G.; Shibuya, K.; Adair-Rohani, H.; AlMazroa, M.A.; Amann, M.; Anderson, H.R.; Andrews, K.G.; et al. A Comparative Risk Assessment of Burden of Disease and Injury Attributable to 67 Risk Factors and Risk Factor Clusters in 21 Regions, 1990-2010: A Systematic Analysis for the Global Burden of Disease Study 2010. Lancet 2012, 380, 2224-2260. [CrossRef]

3. Murray, C.J.L. Disability-Adjusted Life Years (DALYs) for 291 Diseases and Injuries in 21 Regions, 1990-2010: A Systematic Analysis for the Global Burden of Disease Study 2010. Lancet 2012, 380, 27. [CrossRef]

4. Woolf, A.D. Global Burden of Osteoarthritis and Musculoskeletal Diseases. BMC Musculoskelet. Disord. 2015, 16, S3. [CrossRef]

5. Johnell, O.; Kanis, J.A. An Estimate of the Worldwide Prevalence and Disability Associated with Osteoporotic Fractures. Osteoporos. Int. 2006, 8, 1726-1733. [CrossRef] [PubMed]

6. Odén, A.; McCloskey, E.V.; Kanis, J.A.; Harvey, N.C.; Johansson, H. Burden of High Fracture Probability Worldwide: Secular Increases 2010-2040. Osteoporos. Int. 2015, 26, 2243-2248. [CrossRef] [PubMed]

7. Burge, R.; Dawson-Hughes, B.; Solomon, D.H.; Wong, J.B.; King, A.; Tosteson, A. Incidence and Economic Burden of OsteoporosisRelated Fractures in the United States, 2005-2025. J. Bone Miner. Res. 2007, 22, 465-475. [CrossRef]

8. Van Oostwaard, M. Osteoporosis and the Nature of Fragility Fracture: An Overview. In Fragility Fracture Nursing; Perspectives in Nursing Management and Care for Older Adults; Hertz, K., Santy-Tomlinson, J., Eds.; Springer International Publishing: Cham, Switzerland, 2018; pp. 1-13. ISBN 978-3-319-76680-5.

9. Nayak, S.; Edwards, D.L.; Saleh, A.A.; Greenspan, S.L. Systematic Review and Meta-Analysis of the Performance of Clinical Risk Assessment Instruments for Screening for Osteoporosis or Low Bone Density. Osteoporos. Int. 2015, 26, 1543-1554. [CrossRef]

10. Humadi, A.; Alhadithi, R.; Alkudiari, S. Validity of the DEXA Diagnosis of Involutional Osteoporosis in Patients with Femoral Neck Fractures. Indian J. Orthop. 2010, 44, 73. [CrossRef]

11. Sharma, A.K.; Toussaint, N.D.; Elder, G.J.; Masterson, R.; Holt, S.G.; Robertson, P.L.; Ebeling, P.R.; Baldock, P.; Miller, R.C.; Rajapakse, C.S. Magnetic Resonance Imaging Based Assessment of Bone Microstructure as a Non-Invasive Alternative to Histomorphometry in Patients with Chronic Kidney Disease. Bone 2018, 114, 14-21. [CrossRef]

12. Boutroy, S.; Bouxsein, M.L.; Munoz, F.; Delmas, P.D. In Vivo Assessment of Trabecular Bone Microarchitecture by High-Resolution Peripheral Quantitative Computed Tomography. J. Clin. Endocrinol. Metab. 2005, 90, 6508-6515. [CrossRef]

13. Majumdar, S.; Newitt, D.; Mathur, A.; Osman, D.; Gies, A.; Chiu, E.; Lotz, J.; Kinney, J.; Genant, H. Magnetic Resonance Imaging of Trabecular Bone Structure in the Distal Radius: Relationship with X-Ray Tomographic Microscopy and Biomechanics. Osteoporos. Int. 1996, 6, 376-385. [CrossRef]

14. Seifert, A.C.; Li, C.; Rajapakse, C.S.; Bashoor-Zadeh, M.; Bhagat, Y.A.; Wright, A.C.; Zemel, B.S.; Zavaliangos, A.; Wehrli, F.W. Bone Mineral ${ }^{31} \mathrm{P}$ and Matrix-Bound Water Densities Measured by Solid-State ${ }^{31} \mathrm{P}$ and ${ }^{1} \mathrm{H}$ MRI: BONE DENSITY QUANTIFICATION BY MRI. NMR Biomed. 2014, 27, 739-748. [CrossRef] [PubMed]

15. Karamat, M.I.; Darvish-Molla, S.; Santos-Diaz, A. Opportunities and Challenges of 7 Tesla Magnetic Resonance Imaging: A Review. Crit. Rev. Biomed. Eng. 2016, 44, 73-89. [CrossRef]

16. Majumdar, S.; Link, T.M.; Augat, P.; Lin, J.C.; Newitt, D.; Lane, N.E.; Genant, H.K. Trabecular Bone Architecture in the Distal Radius Using Magnetic Resonance Imaging in Subjects with Fractures of the Proximal Femur. Osteoporos. Int. 1999, 10, 231-239. [CrossRef]

17. Krug, R.; Carballido-Gamio, J.; Banerjee, S.; Burghardt, A.J.; Link, T.M.; Majumdar, S. In Vivo Ultra-High-Field Magnetic Resonance Imaging of Trabecular Bone Microarchitecture at 7 T. J. Magn. Reson. Imaging 2008, 27, 854-859. [CrossRef] [PubMed]

18. Chang, G.; Honig, S.; Liu, Y.; Chen, C.; Chu, K.K.; Rajapakse, C.S.; Egol, K.; Xia, D.; Saha, P.K.; Regatte, R.R. 7 Tesla MRI of Bone Microarchitecture Discriminates between Women without and with Fragility Fractures Who Do Not Differ by Bone Mineral Density. J. Bone Miner. Metab 2015, 33, 285-293. [CrossRef]

19. Rajapakse, C.S.; Kobe, E.A.; Batzdorf, A.S.; Hast, M.W.; Wehrli, F.W. Accuracy of MRI-Based Finite Element Assessment of Distal Tibia Compared to Mechanical Testing. Bone 2018, 108, 71-78. [CrossRef]

20. Wang, X.; Nyman, J.S.; Dong, X.; Leng, H.; Reyes, M. Fundamental Biomechanics in Bone Tissue Engineering. Synth. Lect. Tissue Eng. 2010, 2, 1-225. [CrossRef]

21. Fratzl, P.; Gupta, H.S. Nanoscale Mechanisms of Bone Deformation and Fracture. In Handbook of Biomineralization; Buerlein, E., Ed.; Wiley-VCH Verlag GmbH: Weinheim, Germany, 2007; pp. 397-414. ISBN 978-3-527-61944-3.

22. Nyman, J.S.; Roy, A.; Shen, X.; Acuna, R.L.; Tyler, J.H.; Wang, X. The Influence of Water Removal on the Strength and Toughness of Cortical Bone. J. Biomech. 2006, 39, 931-938. [CrossRef]

23. Cowin, S.C. Bone Poroelasticity. J. Biomech. 1999, 32, 217-238. [CrossRef]

24. Brage, S.; Nygard, J.F.; Tellnes, G. The Gender Gap in Musculoskeletal-Related Long Term Sickness Absence in Norway. Scand. J. Soc. Med. 1998, 26, 34-43. [CrossRef] [PubMed]

25. Sebbag, E.; Felten, R.; Sagez, F.; Sibilia, J.; Devilliers, H.; Arnaud, L. The World-Wide Burden of Musculoskeletal Diseases: A Systematic Analysis of the World Health Organization Burden of Diseases Database. Ann. Rheum. Dis. 2019, 78, 844-848. [CrossRef] [PubMed] 
26. International Osteoporosis Foundation; Borgström, F.; Karlsson, L.; Ortsäter, G.; Norton, N.; Halbout, P.; Cooper, C.; Lorentzon, M.; McCloskey, E.V.; Harvey, N.C.; et al. Fragility Fractures in Europe: Burden, Management and Opportunities. Arch. Osteoporos. 2020, 15, 59. [CrossRef]

27. Cheng, X.; Yuan, H.; Cheng, J.; Weng, X.; Xu, H.; Gao, J.; Huang, M.; Wáng, Y.X.J.; Wu, Y.; Xu, W.; et al. Chinese Expert Consensus on the Diagnosis of Osteoporosis by Imaging and Bone Mineral Density. Quant. Imaging Med. Surg. 2020, 10, 12. [CrossRef] [PubMed]

28. Kemmak, A.R.; Rezapour, A.; Jahangiri, R.; Nikjoo, S.; Farabi, H.; Soleimanpour, S. Economic Burden of Osteoporosis in the World: A Systematic Review. Med. J. Islam Repub. Iran 2020. in review.

29. Bartl, R.; Bartl, C. Corticosteroid-Induced Osteoporosis. In Bone Disorders; Springer International Publishing: Cham, Switzerland, 2017; pp. 431-434. ISBN 978-3-319-29180-2.

30. Keenan, H.A.; Maddaloni, E. Bone Microarchitecture in Type 1 Diabetes: It Is Complicated. Curr. Osteoporos. Rep. 2016, 14, 351-358. [CrossRef]

31. Chen, S.C.; Shepherd, S.; McMillan, M.; McNeilly, J.; Foster, J.; Wong, S.C.; Robertson, K.J.; Ahmed, S.F. Skeletal Fragility and Its Clinical Determinants in Children With Type 1 Diabetes. J. Clin. Endocrinol. Metab. 2019, 104, 3585-3594. [CrossRef]

32. Abdalrahaman, N.; McComb, C.; Foster, J.E.; Lindsay, R.S.; Drummond, R.; McKay, G.A.; Perry, C.G.; Ahmed, S.F. The Relationship between Adiposity, Bone Density and Microarchitecture Is Maintained in Young Women Irrespective of Diabetes Status. Clin. Endocrinol. 2017, 87, 327-335. [CrossRef]

33. Singhal, V.; Tulsiani, S.; Campoverde, K.J.; Mitchell, D.M.; Slattery, M.; Schorr, M.; Miller, K.K.; Bredella, M.A.; Misra, M.; Klibanski, A. Impaired Bone Strength Estimates at the Distal Tibia and Its Determinants in Adolescents with Anorexia Nervosa. Bone 2018, 106, 61-68. [CrossRef]

34. Fazeli, P.K.; Klibanski, A. The Paradox of Marrow Adipose Tissue in Anorexia Nervosa. Bone 2019, 118, 47-52. [CrossRef] [PubMed]

35. Fintini, D.; Cianfarani, S.; Cofini, M.; Andreoletti, A.; Ubertini, G.M.; Cappa, M.; Manco, M. The Bones of Children With Obesity. Front. Endocrinol. 2020, 11, 200. [CrossRef] [PubMed]

36. Cordes, C.; Baum, T.; Dieckmeyer, M.; Ruschke, S.; Diefenbach, M.N.; Hauner, H.; Kirschke, J.S.; Karampinos, D.C. MR-Based Assessment of Bone Marrow Fat in Osteoporosis, Diabetes, and Obesity. Front. Endocrinol. 2016, 7. [CrossRef] [PubMed]

37. Cordes, C.; Dieckmeyer, M.; Ott, B.; Shen, J.; Ruschke, S.; Settles, M.; Eichhorn, C.; Bauer, J.S.; Kooijman, H.; Rummeny, E.J.; et al. MR-Detected Changes in Liver Fat, Abdominal Fat, and Vertebral Bone Marrow Fat after a Four-Week Calorie Restriction in Obese Women: MR-Detected Fat Changes After a Diet. J. Magn. Reson. Imaging 2015, 42, 1272-1280. [CrossRef]

38. Ganie, M.A.; Raizada, N.; Chawla, H.; Singh, A.K.; Aggarwala, S.; Bal, C.S. Primary Hyperparathyroidism May Masquerade as Rickets-Osteomalacia in Vitamin D Replete Children. J. Pediatr. Endocrinol. Metab. 2016, 29. [CrossRef]

39. Minisola, S.; Peacock, M.; Fukumoto, S.; Cipriani, C.; Pepe, J.; Tella, S.H.; Collins, M.T. Tumour-Induced Osteomalacia. Nat. Rev. Dis. Prim. 2017, 3, 17044. [CrossRef]

40. Florenzano, P.; Hartley, I.R.; Jimenez, M.; Roszko, K.; Gafni, R.I.; Collins, M.T. Tumor-Induced Osteomalacia. Calcif. Tissue Int. 2021, 108, 128-142. [CrossRef]

41. Ruderman, I.; Rajapakse, C.S.; Opperman, A.; Robertson, P.L.; Masterson, R.; Tiong, M.K.; Toussaint, N.D. Bone Microarchitecture in Patients Undergoing Parathyroidectomy for Management of Secondary Hyperparathyroidism. Bone Rep. 2020, $13,100297$. [CrossRef]

42. Winn, N.; Lalam, R.; Cassar-Pullicino, V. Imaging of Paget's Disease of Bone. Wien. Med. Wochenschr. 2017, 167, 9-17. [CrossRef]

43. Gennari, L.; Rendina, D.; Falchetti, A.; Merlotti, D. Paget's Disease of Bone. Calcif. Tissue Int. 2019, 104, 483-500. [CrossRef]

44. Kravets, I. Paget's Disease of Bone: Diagnosis and Treatment. Am. J. Med. 2018, 131, 1298-1303. [CrossRef]

45. Cundy, T. Paget's Disease of Bone. Metabolism 2018, 80, 5-14. [CrossRef] [PubMed]

46. Appelman-Dijkstra, N.M.; Papapoulos, S.E. Paget's Disease of Bone. Best Pract. Res. Clin. Endocrinol. Metab. 2018, 32, 657-668. [CrossRef] [PubMed]

47. Palomo, T.; Vilaça, T.; Lazaretti-Castro, M. Osteogenesis Imperfecta: Diagnosis and Treatment. Curr. Opin. Endocrinol. Diabetes Obes. 2017, 24, 381-388. [CrossRef] [PubMed]

48. Rossi, V.; Lee, B.; Marom, R. Osteogenesis Imperfecta: Advancements in Genetics and Treatment. Curr. Opin. Pediatr. 2019, 31, 708-715. [CrossRef]

49. Trejo, P.; Rauch, F. Osteogenesis Imperfecta in Children and Adolescents-New Developments in Diagnosis and Treatment. Osteoporos Int 2016, 27, 3427-3437. [CrossRef]

50. Marini, J.C.; Forlino, A.; Bächinger, H.P.; Bishop, N.J.; Byers, P.H.; Paepe, A.D.; Fassier, F.; Fratzl-Zelman, N.; Kozloff, K.M.; Krakow, D.; et al. Osteogenesis Imperfecta. Nat. Rev. Dis. Prim. 2017, 3, 17052. [CrossRef]

51. Hoyer-Kuhn, H.; Netzer, C.; Semler, O. Osteogenesis Imperfecta: Pathophysiology and Treatment. Wien. Med. Wochenschr. 2015, 165, 278-284. [CrossRef]

52. Hermie, I.; Horvath, M.; Van Cauter, S. Temporal Bone Imaging Features in Osteogenesis Imperfecta. J. Belg. Soc. Radiol. 2017, 101, 27. [CrossRef] [PubMed]

53. Ashinsky, B.G.; Fishbein, K.W.; Carter, E.M.; Lin, P.-C.; Pleshko, N.; Raggio, C.L.; Spencer, R.G. Multiparametric Classification of Skin from Osteogenesis Imperfecta Patients and Controls by Quantitative Magnetic Resonance Microimaging. PLoS ONE 2016, 11, e0157891. [CrossRef] [PubMed] 
54. Dwan, K.; Phillipi, C.A.; Steiner, R.D.; Basel, D. Bisphosphonate Therapy for Osteogenesis Imperfecta. Cochrane Database Syst. Rev. 2016. [CrossRef]

55. Casali, P.G.; Bielack, S.; Abecassis, N.; Aro, H.T.; Bauer, S.; Biagini, R.; Bonvalot, S.; Boukovinas, I.; Bovee, J.V.M.G.; Brennan, B.; et al. Bone Sarcomas: ESMO-PaedCan-EURACAN Clinical Practice Guidelines for Diagnosis, Treatment and Follow-Up. Ann. Oncol. 2018, 29, iv79-iv95. [CrossRef] [PubMed]

56. Harrison, D.J.; Geller, D.S.; Gill, J.D.; Lewis, V.O.; Gorlick, R. Current and Future Therapeutic Approaches for Osteosarcoma. Expert Rev. Anticancer Ther. 2018, 18, 39-50. [CrossRef]

57. Hao, Y.; An, R.; Xue, Y.; Li, F.; Wang, H.; Zheng, J.; Fan, L.; Liu, J.; Fan, H.; Yin, H. Prognostic Value of Tumoral and Peritumoral Magnetic Resonance Parameters in Osteosarcoma Patients for Monitoring Chemotherapy Response. Eur. Radiol. 2020. [CrossRef]

58. Saleh, M.M.; Abdelrahman, T.M.; Madney, Y.; Mohamed, G.; Shokry, A.M.; Moustafa, A.F. Multiparametric MRI with DiffusionWeighted Imaging in Predicting Response to Chemotherapy in Cases of Osteosarcoma and Ewing's Sarcoma. BJR 2020, 93, 20200257. [CrossRef] [PubMed]

59. Damilakis, J.; Adams, J.E.; Guglielmi, G.; Link, T.M. Radiation Exposure in X-Ray-Based Imaging Techniques Used in Osteoporosis. Eur. Radiol. 2010, 20, 2707-2714. [CrossRef] [PubMed]

60. Chang, G.; Deniz, C.M.; Honig, S.; Rajapakse, C.S.; Egol, K.; Regatte, R.R.; Brown, R. Feasibility of Three-Dimensional MRI of Proximal Femur Microarchitecture at 3 Tesla Using 26 Receive Elements without and with Parallel Imaging: 3D MRI of Proximal Femur Microarchitecture. J. Magn. Reson. Imaging 2014, 40, 229-238. [CrossRef]

61. Agten, C.A.; Honig, S.; Saha, P.K.; Regatte, R.; Chang, G. Subchondral Bone Microarchitecture Analysis in the Proximal Tibia at 7-T MRI. Acta Radiol. 2018, 59, 716-722. [CrossRef]

62. Guenoun, D.; Pithioux, M.; Souplet, J.-C.; Guis, S.; Le Corroller, T.; Fouré, A.; Pauly, V.; Mattei, J.-P.; Bernard, M.; Guye, M.; et al. Assessment of Proximal Femur Microarchitecture Using Ultra-High Field MRI at 7 Tesla. Diagn. Interv. Imaging 2020, 101, 45-53. [CrossRef]

63. Rad, H.S.; Lam, S.C.B.; Magland, J.F.; Ong, H.; Li, C.; Song, H.K.; Love, J.; Wehrli, F.W. Quantifying Cortical Bone Water in Vivo by Three-Dimensional Ultra-Short Echo-Time MRI: Quantifying Cortical Bone Water In Vivo BY 3D UTE MRI. NMR Biomed. 2011, 24, 855-864. [CrossRef] [PubMed]

64. Adams, J.E. Quantitative Computed Tomography. Eur. J. Radiol. 2009, 71, 415-424. [CrossRef]

65. Majumdar, S.; Genant, H.K.; Grampp, S.; Newitt, D.C.; Truong, V.-H.; Lin, J.C.; Mathur, A. Correlation of Trabecular Bone Structure with Age, Bone Mineral Density, and Osteoporotic Status: In Vivo Studies in the Distal Radius Using High Resolution Magnetic Resonance Imaging. J. Bone Miner. Res. 1997, 12, 111-118. [CrossRef]

66. Ladinsky, G.A.; Vasilic, B.; Popescu, A.M.; Wald, M.; Zemel, B.S.; Snyder, P.J.; Loh, L.; Song, H.K.; Saha, P.K.; Wright, A.C.; et al. Trabecular Structure Quantified With the MRI-Based Virtual Bone Biopsy in Postmenopausal Women Contributes to Vertebral Deformity Burden Independent of Areal Vertebral BMD. J. Bone Miner. Res. 2007, 23, 64-74. [CrossRef]

67. Link, T.M.; Majumdar, S.; Augat, P.; Lin, J.C.; Newitt, D.; Lu, Y.; Lane, N.E.; Genant, H.K. In Vivo High Resolution MRI of the Calcaneus: Differences in Trabecular Structure in Osteoporosis Patients. J. Bone Miner Res. 1998, 13, 1175-1182. [CrossRef]

68. Zhang, X.H.; Liu, X.S.; Vasilic, B.; Wehrli, F.W.; Benito, M.; Rajapakse, C.S.; Snyder, P.J.; Guo, X.E. In Vivo MMRI-Based Finite Element and Morphological Analyses of Tibial Trabecular Bone in Eugonadal and Hypogonadal Men Before and After Testosterone Treatment. J. Bone Miner Res. 2008, 23, 1426-1434. [CrossRef]

69. Zhang, N.; Magland, J.F.; Rajapakse, C.S.; Bhagat, Y.A.; Wehrli, F.W. Potential of in Vivo MRI-Based Nonlinear Finite-Element Analysis for the Assessment of Trabecular Bone Post-Yield Properties: Potential of in Vivo MRI-Based Nonlinear Finite-Element Analysis. Med. Phys. 2013, 40, 052303. [CrossRef] [PubMed]

70. Rajapakse, C.S.; Leonard, M.B.; Bhagat, Y.A.; Sun, W.; Magland, J.F.; Wehrli, F.W. Micro-MR Imaging-Based Computational Biomechanics Demonstrates Reduction in Cortical and Trabecular Bone Strength after Renal Transplantation. Radiology 2012, 262, 912-920. [CrossRef] [PubMed]

71. Krug, R.; Banerjee, S.; Han, E.T.; Newitt, D.C.; Link, T.M.; Majumdar, S. Feasibility of in Vivo Structural Analysis of HighResolution Magnetic Resonance Images of the Proximal Femur. Osteoporos. Int. 2005, 16, 1307-1314. [CrossRef] [PubMed]

72. Chang, G.; Rajapakse, C.S.; Regatte, R.R.; Babb, J.; Saxena, A.; Belmont, H.M.; Honig, S. 3 Tesla MRI Detects Deterioration in Proximal Femur Microarchitecture and Strength in Long-Term Glucocorticoid Users Compared with Controls: Changes in Proximal Femur Microarchitecture in GIO. J. Magn. Reson. Imaging 2015, 42, 1489-1496. [CrossRef] [PubMed]

73. Wehrli, F.W. Structural and Functional Assessment of Trabecular and Cortical Bone by Micro Magnetic Resonance Imaging. J. Magn. Reson. Imaging 2007, 25, 390-409. [CrossRef] [PubMed]

74. Brown, R.; Cheng, Y.; Thompson, M.; Haacke, E.M.; Venkatesan, R. Magnetic Resonance Imaging: Physical Principles and Sequence Design; John Wiley \& Sons: Hoboken, NJ, USA, 2014; ISBN 1-118-63397-0.

75. Techawiboonwong, A.; Song, H.K.; Magland, J.F.; Saha, P.K.; Wehrli, F.W. Implications of Pulse Sequence in Structural Imaging of Trabecular Bone. J. Magn. Reson. Imaging 2005, 22, 647-655. [CrossRef]

76. Chang, G.; Boone, S.; Martel, D.; Rajapakse, C.S.; Hallyburton, R.S.; Valko, M.; Honig, S.; Regatte, R.R. MRI Assessment of Bone Structure and Microarchitecture: Bone Structure and Microarchitecture. J. Magn. Reson. Imaging 2017, 46, 323-337. [CrossRef]

77. Krug, R.; Carballido-Gamio, J.; Burghardt, A.J.; Kazakia, G.; Hyun, B.H.; Jobke, B.; Banerjee, S.; Huber, M.; Link, T.M.; Majumdar, S. Assessment of Trabecular Bone Structure Comparing Magnetic Resonance Imaging at 3 Tesla with High-Resolution Peripheral Quantitative Computed Tomography Ex Vivo and in Vivo. Osteoporos. Int. 2008, 19, 653-661. [CrossRef] 
78. Pritchard, J.M.; Giangregorio, L.M.; Atkinson, S.A.; Beattie, K.A.; Inglis, D.; Ioannidis, G.; Gerstein, H.; Punthakee, Z.; Adachi, J.D.; Papaioannou, A. Changes in Trabecular Bone Microarchitecture in Postmenopausal Women with and without Type 2 Diabetes: A Two Year Longitudinal Study. BMC Musculoskelet. Disord. 2013, 14, 114. [CrossRef]

79. Link, T.M.; Vieth, V.; Stehling, C.; Lotter, A.; Beer, A.; Newitt, D.; Majumdar, S. High-Resolution MRI vs Multislice Spiral CT: Which Technique Depicts the Trabecular Bone Structure Best? Eur. Radiol. 2003, 13, 663-671. [CrossRef] [PubMed]

80. Link, T.M.; Vieth, V.; Langenberg, R.; Meier, N.; Lotter, A.; Newitt, D.; Majumdar, S. Structure Analysis of High Resolution Magnetic Resonance Imaging of the Proximal Femur: In Vitro Correlation with Biomechanical Strength and BMD. Calcif. Tissue Int. 2003, 72, 156-165. [CrossRef] [PubMed]

81. Rajapakse, C.S.; Magland, J.F.; Wald, M.J.; Liu, X.S.; Zhang, X.H.; Guo, X.E.; Wehrli, F.W. Computational Biomechanics of the Distal Tibia from High-Resolution MR and Micro-CT Images. Bone 2010, 47, 556-563. [CrossRef] [PubMed]

82. Modlesky, C.M.; Subramanian, P.; Miller, F. Underdeveloped Trabecular Bone Microarchitecture Is Detected in Children with Cerebral Palsy Using High-Resolution Magnetic Resonance Imaging. Osteoporos. Int. 2008, 19, 169-176. [CrossRef] [PubMed]

83. Rajapakse, C.S.; Phillips, E.A.; Sun, W.; Wald, M.J.; Magland, J.F.; Snyder, P.J.; Wehrli, F.W. Vertebral Deformities and Fractures Are Associated with MRI and PQCT Measures Obtained at the Distal Tibia and Radius of Postmenopausal Women. Osteoporos. Int. 2014, 25, 973-982. [CrossRef] [PubMed]

84. Soldati, E.; Bendahan, D.; Pithioux, M.; Vicente, J. MRI Assessment of Bone Microarchitecture in Human Bone Samples: The Issue of Air Bubbles Artefacts. Bone Rep. 2020, 13, 100541. [CrossRef]

85. Baum, T. Use of MR-Based Trabecular Bone Microstructure Analysis at the Distal Radius for Osteoporosis Diagnostics: A Study in Post-Menopausal Women with Breast Cancer and Treated with Aromatase Inhibitor. Clin. Cases Miner. Bone Metab. 2016. [CrossRef]

86. Liu, C.; Liu, C.; Ren, X.; Si, L.; Shen, H.; Wang, Q.; Yao, W. Quantitative Evaluation of Subchondral Bone Microarchitecture in Knee Osteoarthritis Using 3T MRI. BMC Musculoskelet. Disord. 2017, 18, 496. [CrossRef]

87. MacKay, J.W.; Murray, P.J.; Kasmai, B.; Johnson, G.; Donell, S.T.; Toms, A.P. Subchondral Bone in Osteoarthritis: Association between MRI Texture Analysis and Histomorphometry. Osteoarthr. Cartil. 2017, 25, 700-707. [CrossRef]

88. Chiba, K.; Uetani, M.; Kido, Y.; Ito, M.; Okazaki, N.; Taguchi, K.; Shindo, H. Osteoporotic Changes of Subchondral Trabecular Bone in Osteoarthritis of the Knee: A 3-T MRI Study. Osteoporos. Int. 2012, 23, 589-597. [CrossRef] [PubMed]

89. Soldati, E.; Pithioux, M.; Vicente, J.; Bendahan, D. Trabecular Bone Microarchitecture: A Comparative Analysis between High Field, Ultra High Field MRI and X-Ray Micro CT in Humans Anatomical Samples. Bone Rep. 2020, 13, 100542. [CrossRef]

90. Guenoun, D.; Fouré, A.; Pithioux, M.; Guis, S.; Le Corroller, T.; Mattei, J.-P.; Pauly, V.; Guye, M.; Bernard, M.; Chabrand, P.; et al. Correlative Analysis of Vertebral Trabecular Bone Microarchitecture and Mechanical Properties: A Combined Ultra-High Field (7 Tesla) MRI and Biomechanical Investigation. SPINE 2017, 42, E1165-E1172. [CrossRef]

91. Rajapakse, C.S.; Magland, J.; Zhang, X.H.; Liu, X.S.; Wehrli, S.L.; Guo, X.E.; Wehrli, F.W. Implications of Noise and Resolution on Mechanical Properties of Trabecular Bone Estimated by Image-Based Finite-Element Analysis. J. Orthop. Res. 2009, 27, 1263-1271. [CrossRef] [PubMed]

92. Hipp, J.A.; Jansujwicz, A.; Simmons, C.A.; Snyder, B.D. Trabecular Bone Morphology from Micro-Magnetic Resonance Imaging. J. Bone Miner. Res. 2009, 11, 286-292. [CrossRef]

93. Zaia, A.; Rossi, R.; Galeazzi, R.; Sallei, M.; Maponi, P.; Scendoni, P. Fractal Lacunarity of Trabecular Bone in Vertebral MRI to Predict Osteoporotic Fracture Risk in Over-Fifties Women. The LOTO Study. BMC Musculoskelet. Disord. 2021, 22, 108. [CrossRef]

94. Kijowski, R.; Tuite, M.; Kruger, D.; Munoz Del Rio, A.; Kleerekoper, M.; Binkley, N. Evaluation of Trabecular Microarchitecture in Nonosteoporotic Postmenopausal Women with and without Fracture. J. Bone Miner. Res. 2012, 27, 1494-1500. [CrossRef] [PubMed]

95. Kazakia, G.J.; Carballido-Gamio, J.; Lai, A.; Nardo, L.; Facchetti, L.; Pasco, C.; Zhang, C.A.; Han, M.; Parrott, A.H.; Tien, P.; et al. Trabecular Bone Microstructure Is Impaired in the Proximal Femur of Human Immunodeficiency Virus-Infected Men with Normal Bone Mineral Density. Quant. Imaging Med. Surg. 2018, 8, 5-13. [CrossRef]

96. Leonard, M.B.; Wehrli, F.W.; Ziolkowski, S.L.; Billig, E.; Long, J.; Nickolas, T.L.; Magland, J.F.; Nihtianova, S.; Zemel, B.S.; Herskovitz, R.; et al. A Multi-Imaging Modality Study of Bone Density, Bone Structure and the Muscle Bone Unit in End-Stage Renal Disease. Bone 2019, 127, 271-279. [CrossRef]

97. Sharma, A.K.; Toussaint, N.D.; Elder, G.J.; Rajapakse, C.S.; Holt, S.G.; Baldock, P.; Robertson, P.L.; Ebeling, P.R.; Sorci, O.R.; Masterson, R. Changes in Bone Microarchitecture Following Kidney Transplantation-Beyond Bone Mineral Density. Clin. Transplant. 2018, 32, e13347. [CrossRef]

98. Griffin, L.M.; Honig, S.; Chen, C.; Saha, P.K.; Regatte, R.; Chang, G. 7T MRI of Distal Radius Trabecular Bone Microarchitecture: How Trabecular Bone Quality Varies Depending on Distance from End-of-Bone: 7T MRI of Distal Radius. J. Magn. Reson. Imaging 2017, 45, 872-878. [CrossRef]

99. Kang, C.; Paley, M.; Ordidge, R.; Speller, R. In Vivo MRI Measurements of Bone Quality in the Calcaneus: A Comparison with DXA and Ultrasound. Osteoporos. Int. 1999, 9, 65-74. [CrossRef]

100. Guglielmi, G.; Selby, K.; Blunt, B.A.; Jergas, M.; Newitt, D.C.; Genant, H.K.; Majumdar, S. Magnetic Resonance Imaging of the Calcaneus: Preliminary Assessment of Trabecular Bone-Dependent Regional Variations in Marrow Relaxation Time Compared with Dual X-Ray Absorptiometry. Acad. Radiol. 1996, 3, 336-343. [CrossRef] 
101. Arokoski, M.H.; Arokoski, J.P.A.; Vainio, P.; Niemitukia, L.H.; Kröger, H.; Jurvelin, J.S. Comparison of DXA and MRI Methods for Interpreting Femoral Neck Bone Mineral Density. J. Clin. Densitom. 2002, 5, 289-296. [CrossRef]

102. Brismar, T.B. MR Relaxometry of Lumbar Spine, Hip, and Calcaneus in Healthy Premenopausal Women: Relationship with Dual Energy X-Ray Absorptiometry and Quantitative Ultrasound. Eur. Radiol. 2000, 10, 1215-1221. [CrossRef]

103. Grampp, S.; Majumdar, S.; Jergas, M.; Newitt, D.; Lang, P.; Harry, K. Genant Distal Radius: In Vivo Assessment with Quantitative MR Imaging, Peripheral Quantitative CT, and Dual X-Ray Absorptiometry. Radiology 1996. [CrossRef] [PubMed]

104. Schmeel, F.C.; Luetkens, J.A.; Feißt, A.; Enkirch, S.J.; Endler, C.H.-J.; Wagenhäuser, P.J.; Schmeel, L.C.; Träber, F.; Schild, H.H.; Kukuk, G.M. Quantitative Evaluation of T2* Relaxation Times for the Differentiation of Acute Benign and Malignant Vertebral Body Fractures. Eur. J. Radiol. 2018, 108, 59-65. [CrossRef]

105. Shen, W.; Chen, J.; Punyanitya, M.; Shapses, S.; Heshka, S.; Heymsfield, S.B. MRI-Measured Bone Marrow Adipose Tissue Is Inversely Related to DXA-Measured Bone Mineral in Caucasian Women. Osteoporos. Int. 2007, 18, 641-647. [CrossRef]

106. Griffith, J.F.; Yeung, D.K.W.; Antonio, G.E.; Lee, F.K.H.; Hong, A.W.L.; Wong, S.Y.S.; Lau, E.M.C.; Leung, P.C. Vertebral Bone Mineral Density, Marrow Perfusion, and Fat Content in Healthy Men and Men with Osteoporosis: Dynamic Contrast-Enhanced MR Imaging and MR Spectroscopy. Radiology 2005, 236, 945-951. [CrossRef] [PubMed]

107. Woods, G.N.; Ewing, S.K.; Sigurdsson, S.; Kado, D.M.; Eiriksdottir, G.; Gudnason, V.; Hue, T.F.; Lang, T.F.; Vittinghoff, E.; Harris, T.B.; et al. Greater Bone Marrow Adiposity Predicts Bone Loss in Older Women. J. Bone Miner. Res. 2020, 35, 326-332. [CrossRef]

108. Chang, G.; Rajapakse, C.S.; Chen, C.; Welbeck, A.; Egol, K.; Regatte, R.R.; Saha, P.K.; Honig, S. 3-T MR Imaging of Proximal Femur Microarchitecture in Subjects with and without Fragility Fracture and Nonosteoporotic Proximal Femur Bone Mineral Density. Radiology 2018, 287, 608-619. [CrossRef] [PubMed]

109. Kindler, J.M.; Pollock, N.K.; Ross, H.L.; Modlesky, C.M.; Singh, H.; Laing, E.M.; Lewis, R.D. Obese Versus Normal-Weight Late-Adolescent Females Have Inferior Trabecular Bone Microarchitecture: A Pilot Case-Control Study. Calcif. Tissue Int. 2017, 101, 479-488. [CrossRef]

110. Koshi, R. Cunningham's Manual of Practical Anatomy VOL 1 Upper and Lower Limbs, 16th ed.; OUP: Oxford, UK, 2017; Volume 1, ISBN 978-0-19-874936-3.

111. Mulder, M.J.; Keuken, M.C.; Bazin, P.-L.; Alkemade, A.; Forstmann, B.U. Size and Shape Matter: The Impact of Voxel Geometry on the Identification of Small Nuclei. PLoS ONE 2019, 14, e0215382. [CrossRef] [PubMed]

112. Liu, C.; Liu, C.; Si, L.; Shen, H.; Wang, Q.; Yao, W. Relationship between Subchondral Bone Microstructure and Articular Cartilage in the Osteoarthritic Knee Using 3T MRI: Interrelationships in the OA Knee. J. Magn. Reson. Imaging 2018, 48, 669-679. [CrossRef]

113. Bolbos, R.I.; Zuo, J.; Banerjee, S.; Link, T.M.; Benjamin Ma, C.; Li, X.; Majumdar, S. Relationship between Trabecular Bone Structure and Articular Cartilage Morphology and Relaxation Times in Early OA of the Knee Joint Using Parallel MRI at 3T. Osteoarthr. Cartil. 2008, 16, 1150-1159. [CrossRef]

114. Abdulaal, O.M. Evaluation of Optimised 3D Turbo Spin Echo and Gradient Echo MR Pulse Sequences of the Knee at 3T and 1.5T. 9. Radiography 2020. [CrossRef]

115. Folkesson, J.; Goldenstein, J.; Carballido-Gamio, J.; Kazakia, G.; Burghardt, A.J.; Rodriguez, A.; Krug, R.; de Papp, A.E.; Link, T.M.; Majumdar, S. Longitudinal Evaluation of the Effects of Alendronate on MRI Bone Microarchitecture in Postmenopausal Osteopenic Women. Bone 2011, 48, 611-621. [CrossRef]

116. Jarraya, M.; Heiss, R.; Duryea, J.; Nagel, A.M.; Lynch, J.A.; Guermazi, A.; Weber, M.-A.; Arkudas, A.; Horch, R.E.; Uder, M.; et al. Bone Structure Analysis of the Radius Using Ultrahigh Field (7T) MRI: Relevance of Technical Parameters and Comparison with 3T MRI and Radiography. Diagnostics 2021, 11, 110. [CrossRef]

117. Weiger, M.; Stampanoni, M.; Pruessmann, K.P. Direct Depiction of Bone Microstructure Using MRI with Zero Echo Time. Bone 2013, 54, 44-47. [CrossRef]

118. Kazakia, G.J.; Hyun, B.; Burghardt, A.J.; Krug, R.; Newitt, D.C.; de Papp, A.E.; Link, T.M.; Majumdar, S. In Vivo Determination of Bone Structure in Postmenopausal Women: A Comparison of HR-PQCT and High-Field MR Imaging. J. Bone Miner. Res. 2007, 23, 463-474. [CrossRef]

119. Wu, H.-Z.; Zhang, X.-F.; Han, S.-M.; Cao, L.; Wen, J.-X.; Wu, W.-J.; Gao, B.-L. Correlation of Bone Mineral Density with MRI T2* Values in Quantitative Analysis of Lumbar Osteoporosis. Arch. Osteoporos 2020, 15, 18. [CrossRef] [PubMed]

120. Bandirali, M.; Leo, G.D.; Papini, G.D.E.; Messina, C.; Sconfienza, L.M.; Ulivieri, F.M.; Sardanelli, F. A New Diagnostic Score to Detect Osteoporosis in Patients Undergoing Lumbar Spine MRI. Eur. Radiol. 2015, 25, 2951-2959. [CrossRef] [PubMed]

121. Fazeli, P.K.; Horowitz, M.C.; MacDougald, O.A.; Scheller, E.L.; Rodeheffer, M.S.; Rosen, C.J.; Klibanski, A. Marrow Fat and Bone-New Perspectives. J. Clin. Endocrinol. Metab. 2013, 98, 935-945. [CrossRef] [PubMed]

122. Sollmann, N.; Löffler, M.T.; Kronthaler, S.; Böhm, C.; Dieckmeyer, M.; Ruschke, S.; Kirschke, J.S.; Carballido-Gamio, J.; Karampinos, D.C.; Krug, R.; et al. MRI-Based Quantitative Osteoporosis Imaging at the Spine and Femur. J. Magn. Reason. Imaging 2020, jmri.27260. [CrossRef]

123. Reeder, S.B.; Hu, H.H.; Sirlin, C.B. Proton Density Fat-Fraction: A Standardized Mr-Based Biomarker of Tissue Fat Concentration. J. Magn. Reson. Imaging 2012, 36, 1011-1014. [CrossRef] [PubMed]

124. Chang, R.; Ma, X.; Jiang, Y.; Huang, D.; Chen, X.; Zhang, M.; Hao, D. Percentage Fat Fraction in Magnetic Resonance Imaging: Upgrading the Osteoporosis-Detecting Parameter. BMC Med. Imaging 2020, 20, 30. [CrossRef]

125. He, J.; Fang, H.; Li, X. Vertebral Bone Marrow Fat Content in Normal Adults with Varying Bone Densities at 3T Magnetic Resonance Imaging. Acta Radiol 2019, 60, 509-515. [CrossRef] 
126. Karampinos, D.C.; Ruschke, S.; Gordijenko, O.; Garcia, E.G.; Kooijman, H.; Burgkart, R.; Rummeny, E.J.; Bauer, J.S.; Baum, T. Association of MRS-Based Vertebral Bone Marrow Fat Fraction with Bone Strength in a Human In Vitro Model. J. Osteoporos. 2015, 2015, 152349. [CrossRef] [PubMed]

127. Sheu, Y.; Amati, F.; Schwartz, A.V.; Danielson, M.E.; Li, X.; Boudreau, R.; Cauley, J.A. Vertebral Bone Marrow Fat, Bone Mineral Density and Diabetes: The Osteoporotic Fractures in Men (MrOS) Study. Bone 2017, 97, 299-305. [CrossRef] [PubMed]

128. Manenti, G.; Capuani, S.; Fanucci, E.; Assako, E.P.; Masala, S.; Sorge, R.; Iundusi, R.; Tarantino, U.; Simonetti, G. Diffusion Tensor Imaging and Magnetic Resonance Spectroscopy Assessment of Cancellous Bone Quality in Femoral Neck of Healthy, Osteopenic and Osteoporotic Subjects at 3T: Preliminary Experience. Bone 2013, 55, 7-15. [CrossRef]

129. Pietro, G.D.; Capuani, S.; Manenti, G.; Vinicola, V.; Fusco, A.; Baldi, J.; Scimeca, M.; Hagberg, G.; Bozzali, M.; Simonetti, G.; et al. Bone Marrow Lipid Profiles from Peripheral Skeleton as Potential Biomarkers for Osteoporosis: A 1H-MR Spectroscopy Study. Acad. Radiol. 2016, 23, 273-283. [CrossRef]

130. Ismail, U.N.; Azlan, C.A.; Khairullah, S.; Azman, R.R.; Omar, N.F.; Md Shah, M.N.; Yeong, C.H.; Jackson, N.; Ng, K.H. Marrow Fat Content and Composition in B-Thalassemia: A Study Using ${ }^{1}$ H-MRS. J. Magn. Reason. Imaging 2021, 53, 190-198. [CrossRef] [PubMed]

131. Yu, E.W.; Greenblatt, L.; Eajazi, A.; Torriani, M.; Bredella, M.A. Marrow Adipose Tissue Composition in Adults with Morbid Obesity. Bone 2017, 97, 38-42. [CrossRef]

132. Singhal, V.; Bredella, M.A. Marrow Adipose Tissue Imaging in Humans. Bone 2019, 118, 69-76. [CrossRef] [PubMed]

133. Karampinos, D.C.; Ruschke, S.; Dieckmeyer, M.; Diefenbach, M.; Franz, D.; Gersing, A.S.; Krug, R.; Baum, T. Quantitative MRI and Spectroscopy of Bone Marrow: Quantitative MR of Bone Marrow. J. Magn. Reson. Imaging 2018, 47, 332-353. [CrossRef]

134. Ruschke, S.; Pokorney, A.; Baum, T.; Eggers, H.; Miller, J.H.; Hu, H.H.; Karampinos, D.C. Measurement of Vertebral Bone Marrow Proton Density Fat Fraction in Children Using Quantitative Water-Fat MRI. Magn. Reason. Mater. Phys. Biol. Med. 2017, 30, 449-460. [CrossRef]

135. Li, G.; Xu, Z.; Gu, H.; Li, X.; Yuan, W.; Chang, S.; Fan, J.; Calimente, H.; Hu, J. Comparison of Chemical Shift-Encoded Water-Fat MRI and MR Spectroscopy in Quantification of Marrow Fat in Postmenopausal Females: Water-Fat Imaging Quantifies Marrow Fat. J. Magn. Reson. Imaging 2017, 45, 66-73. [CrossRef]

136. Ruschke, S.; Eggers, H.; Kooijman, H.; Diefenbach, M.N.; Baum, T.; Haase, A.; Rummeny, E.J.; Hu, H.H.; Karampinos, D.C. Correction of Phase Errors in Quantitative Water-Fat Imaging Using a Monopolar Time-Interleaved Multi-Echo Gradient Echo Sequence: Phase Error Correction in Time-Interleaved Water-Fat Imaging. Magn. Reson. Med. 2017, 78, 984-996. [CrossRef]

137. Martel, D.; Leporq, B.; Saxena, A.; Belmont, H.M.; Turyan, G.; Honig, S.; Regatte, R.R.; Chang, G. 3T Chemical Shift-encoded MRI: Detection of Altered Proximal Femur Marrow Adipose Tissue Composition in Glucocorticoid Users and Validation with Magnetic Resonance Spectroscopy. J. Magn. Reson. Imaging 2018, 50, 490-496. [CrossRef]

138. Zhao, Y.; Huang, M.; Ding, J.; Zhang, X.; Spuhler, K.; Hu, S.; Li, M.; Fan, W.; Chen, L.; Zhang, X.; et al. Prediction of Abnormal Bone Density and Osteoporosis from Lumbar Spine MR Using Modified Dixon Quant in 257 Subjects with Quantitative Computed Tomography as Reference: Bone Density Prediction From MDixon MR. J. Magn. Reson. Imaging 2019, 49, 390-399. [CrossRef] [PubMed]

139. Martel, D.; Leporq, B.; Bruno, M.; Regatte, R.R.; Honig, S.; Chang, G. Chemical Shift-Encoded MRI for Assessment of Bone Marrow Adipose Tissue Fat Composition: Pilot Study in Premenopausal versus Postmenopausal Women. Magn. Reson. Imaging 2018, 53, 148-155. [CrossRef]

140. Schmeel, F.C.; Luetkens, J.A.; Enkirch, S.J.; Feißt, A.; Endler, C.H.-J.; Schmeel, L.C.; Wagenhäuser, P.J.; Träber, F.; Schild, H.H.; Kukuk, G.M. Proton Density Fat Fraction (PDFF) MR Imaging for Differentiation of Acute Benign and Neoplastic Compression Fractures of the Spine. Eur. Radiol. 2018, 28, 5001-5009. [CrossRef]

141. Dieckmeyer, M.; Junker, D.; Ruschke, S.; Mookiah, M.R.K.; Subburaj, K.; Burian, E.; Sollmann, N.; Kirschke, J.S.; Karampinos, D.C.; Baum, T. Vertebral Bone Marrow Heterogeneity Using Texture Analysis of Chemical Shift Encoding-Based MRI: Variations in Age, Sex, and Anatomical Location. Front. Endocrinol. 2020, 11, 555931. [CrossRef]

142. Baum, T.; Yap, S.P.; Dieckmeyer, M.; Ruschke, S.; Eggers, H.; Kooijman, H.; Rummeny, E.J.; Bauer, J.S.; Karampinos, D.C. Assessment of Whole Spine Vertebral Bone Marrow Fat Using Chemical Shift-Encoding Based Water-Fat MRI: Whole Spine Water-Fat Imaging. J. Magn. Reson. Imaging 2015, 42, 1018-1023. [CrossRef]

143. Gómez, M.P.A.; Benavent, C.A.; Simoni, P.; Aparisi, F.; Guglielmi, G.; Bazzocchi, A. Fat and Bone: The Multiperspective Analysis of a Close Relationship. Quant. Imaging Med. Surg. 2020, 10, 22.

144. Haacke, E.M.; Xu, Y.; Cheng, Y.-C.N.; Reichenbach, J.R. Susceptibility Weighted Imaging (SWI). Magn. Reson. Med. 2004, 52, 612-618. [CrossRef]

145. Rauscher, A.; Sedlacik, J.; Deistung, A.; Mentzel, H.-J.; Reichenbach, J.R. Susceptibility Weighted Imaging: Data Acquisition, Image Reconstruction and Clinical Applications. Zeitschrift für Medizinische Physik 2006, 16, 240-250. [CrossRef]

146. Schweser, F.; Deistung, A.; Reichenbach, J.R. Foundations of MRI Phase Imaging and Processing for Quantitative Susceptibility Mapping (QSM). Z. Med. Phys. 2016, 26, 6-34. [CrossRef]

147. Deistung, A.; Schweser, F.; Reichenbach, J.R. Overview of Quantitative Susceptibility Mapping: Overview of Quantitative Susceptibility Mapping. NMR Biomed. 2017, 30, e3569. [CrossRef] 
148. Dimov, A.V.; Liu, Z.; Spincemaille, P.; Prince, M.R.; Du, J.; Wang, Y. Bone Quantitative Susceptibility Mapping Using a Chemical Species-Specific $R_{2}{ }^{*}$ Signal Model with Ultrashort and Conventional Echo Data: Bone QSM Using a $R_{2}{ }^{*}$ Signal Model With UTE Conventional Echo Data. Magn. Reson. Med. 2018, 79, 121-128. [CrossRef] [PubMed]

149. Chen, W.; Zhu, W.; Kovanlikaya, I.; Kovanlikaya, A.; Liu, T.; Wang, S.; Salustri, C.; Wang, Y. Intracranial Calcifications and Hemorrhages: Characterization with Quantitative Susceptibility Mapping. Radiology 2014, 270, 496-505. [CrossRef]

150. Haacke, E.M.; Liu, S.; Buch, S.; Zheng, W.; Wu, D.; Ye, Y. Quantitative Susceptibility Mapping: Current Status and Future Directions. Magn. Reson. Imaging 2015, 33, 1-25. [CrossRef] [PubMed]

151. Li, W.; Wu, B.; Liu, C. Quantitative Susceptibility Mapping of Human Brain Reflects Spatial Variation in Tissue Composition. NeuroImage 2011, 55, 1645-1656. [CrossRef]

152. Du, J.; Hermida, J.C.; Diaz, E.; Corbeil, J.; Znamirowski, R.; D’Lima, D.D.; Bydder, G.M. Assessment of Cortical Bone with Clinical and Ultrashort Echo Time Sequences. Magn. Reson. Med. 2013, 70, 697-704. [CrossRef]

153. Chen, Y.; Guo, Y.; Zhang, X.; Mei, Y.; Feng, Y.; Zhang, X. Bone Susceptibility Mapping with MRI Is an Alternative and Reliable Biomarker of Osteoporosis in Postmenopausal Women. Eur Radiol. 2018, 28, 5027-5034. [CrossRef] [PubMed]

154. Diefenbach, M.N.; Meineke, J.; Ruschke, S.; Baum, T.; Gersing, A.; Karampinos, D.C. On the Sensitivity of Quantitative Susceptibility Mapping for Measuring Trabecular Bone Density. Magn. Reson. Med. 2019, 81, 1739-1754. [CrossRef]

155. Lu, X.; Jang, H.; Ma, Y.; Jerban, S.; Chang, E.; Du, J. Ultrashort Echo Time Quantitative Susceptibility Mapping (UTE-QSM) of Highly Concentrated Magnetic Nanoparticles: A Comparison Study about Different Sampling Strategies. Molecules 2019, $24,1143$. [CrossRef]

156. Jerban, S.; Lu, X.; Jang, H.; Ma, Y.; Namiranian, B.; Le, N.; Li, Y.; Chang, E.Y.; Du, J. Significant Correlations between Human Cortical Bone Mineral Density and Quantitative Susceptibility Mapping (QSM) Obtained with 3D Cones Ultrashort Echo Time Magnetic Resonance Imaging (UTE-MRI). Magn. Reson. Imaging 2019, 62, 104-110. [CrossRef]

157. Seifert, A.C.; Wehrli, F.W. Solid-State Quantitative ${ }^{1} \mathrm{H}$ and ${ }^{31} \mathrm{P}$ MRI of Cortical Bone in Humans. Curr. Osteoporos. Rep. 2016, 14, 77-86. [CrossRef]

158. Gervais, C.; Bonhomme, C.; Laurencin, D. Recent Directions in the Solid-State NMR Study of Synthetic and Natural Calcium Phosphates. Solid State Nucl. Magn. Reson. 2020, 107, 101663. [CrossRef]

159. Glover, G.H.; Pauly, J.M.; Bradshaw, K.M. Boron-11 Imaging with a Three-Dimensional Reconstruction Method. J. Magn. Reson. Imaging 1992, 2, 47-52. [CrossRef]

160. Weiger, M.; Pruessmann, K.P.; Hennel, F. MRI with Zero Echo Time: Hard versus Sweep Pulse Excitation: MRI With Zero Echo Time. Magn. Reson. Med. 2011, 66, 379-389. [CrossRef]

161. Jerban, S.; Chang, D.G.; Ma, Y.; Jang, H.; Chang, E.Y.; Du, J. An Update in Qualitative Imaging of Bone Using Ultrashort Echo Time Magnetic Resonance. Front. Endocrinol. 2020, 11, 555756. [CrossRef] [PubMed]

162. Idiyatullin, D.; Corum, C.; Park, J.-Y.; Garwood, M. Fast and Quiet MRI Using a Swept Radiofrequency. J. Magn. Reson. 2006, 181, 342-349. [CrossRef] [PubMed]

163. Idiyatullin, D.; Suddarth, S.; Corum, C.A.; Adriany, G.; Garwood, M. Continuous SWIFT. J. Magn. Reson. 2012, 220 , 26-31. [CrossRef] [PubMed]

164. Mastrogiacomo, S.; Dou, W.; Jansen, J.A.; Walboomers, X.F. Magnetic Resonance Imaging of Hard Tissues and Hard Tissue Engineered Bio-Substitutes. Mol. Imaging Biol 2019, 21, 1003-1019. [CrossRef] [PubMed]

165. Takizawa, M.; Hanada, H.; Oka, K.; Takahashi, T.; Yamamoto, E.; Fujii, M. A Robust Ultrashort TE (UTE) Imaging Method With Corrected k-Space Trajectory by Using Parametric Multiple Function Model of Gradient Waveform. IEEE Trans. Med Imaging 2013, 32, 11. [CrossRef]

166. Kuethe, D.O.; Caprihan, A.; Lowe, I.J.; Madio, D.P.; Gach, H.M. Transforming NMR Data Despite Missing Points. J. Magn. Reson. 1999, 139, 18-25. [CrossRef] [PubMed]

167. Wu, Y.; Ackerman, J.L.; Chesler, D.A.; Graham, L.; Wang, Y.; Glimcher, M.J. Density of Organic Matrix of Native Mineralized Bone Measured by Water- and Fat-Suppressed Proton Projection MRI. Magn. Reson. Med. 2003, 50, 59-68. [CrossRef]

168. Grodzki, D.M.; Jakob, P.M.; Heismann, B. Ultrashort Echo Time Imaging Using Pointwise Encoding Time Reduction with Radial Acquisition (PETRA). Magn. Reson. Med. 2012, 67, 510-518. [CrossRef] [PubMed]

169. Idiyatullin, D.; Corum, C.A.; Nixdorf, D.R.; Garwood, M. Intraoral Approach for Imaging Teeth Using the Transverse $B{ }_{1}$ Field Components of an Occlusally Oriented Loop Coil: Intraoral Approach for Imaging Teeth. Magn. Reson. Med. 2014, 72, 160-165. [CrossRef]

170. Zhao, X.; Song, H.K.; Seifert, A.C.; Li, C.; Wehrli, F.W. Feasibility of Assessing Bone Matrix and Mineral Properties in Vivo by Combined Solid-State ${ }^{1} \mathrm{H}$ and ${ }^{31} \mathrm{P}$ MRI. PLoS ONE 2017, 12, e0173995. [CrossRef]

171. Techawiboonwong, A.; Song, H.K.; Leonard, M.B.; Wehrli, F.W. Cortical Bone Water: In Vivo Quantification with Ultrashort Echo-Time MR Imaging. Radiology 2008, 248, 824-833. [CrossRef]

172. Manhard, M.K.; Horch, R.A.; Gochberg, D.F.; Nyman, J.S.; Does, M.D. In Vivo Quantitative MR Imaging of Bound and Pore Water in Cortical Bone. Radiology 2015, 277, 221-229. [CrossRef]

173. Chen, J.; Carl, M.; Ma, Y.; Shao, H.; Lu, X.; Chen, B.; Chang, E.Y.; Wu, Z.; Du, J. Fast Volumetric Imaging of Bound and Pore Water in Cortical Bone Using Three-Dimensional Ultrashort-TE (UTE) and Inversion Recovery UTE Sequences: Bound and Pore Water Imaging in Cortical Bone Using 3D UTE Sequences. NMR Biomed. 2016, 29, 1373-1380. [CrossRef] 
174. Jerban, S.; Ma, Y.; Li, L.; Jang, H.; Wan, L.; Guo, T.; Searleman, A.; Chang, E.Y.; Du, J. Volumetric Mapping of Bound and Pore Water as Well as Collagen Protons in Cortical Bone Using 3D Ultrashort Echo Time Cones MR Imaging Techniques. Bone 2019, 127, 120-128. [CrossRef]

175. Kaflak, A.; Chmielewski, D.; Kolodziejski, W. Solid-State NMR Study of Discrete Environments of Bone Mineral Nanoparticles Using Phosphorus-31 Relaxation. J. Appl. Biomed. 2016, 14, 321-330. [CrossRef]

176. Rajapakse, C.S.; Bashoor-Zadeh, M.; Li, C.; Sun, W.; Wright, A.C.; Wehrli, F.W. Volumetric Cortical Bone Porosity Assessment with MR Imaging: Validation and Clinical Feasibility. Radiology 2015, 276, 526-535. [CrossRef] [PubMed]

177. Tamimi, I.; Cortes, A.R.G.; Sánchez-Siles, J.-M.; Ackerman, J.L.; González-Quevedo, D.; García, Á.; Yaghoubi, F.; Abdallah, M.-N.; Eimar, H.; Alsheghri, A.; et al. Composition and Characteristics of Trabecular Bone in Osteoporosis and Osteoarthritis. Bone 2020, 140, 115558. [CrossRef] [PubMed]

178. Zhao, X.; Song, H.K.; Wehrli, F.W. In Vivo Bone ${ }^{31}$ P Relaxation Times and Their Implications on Mineral Quantification. Magn. Reson. Med. 2018, 80, 2514-2524. [CrossRef]

179. Li, C.; Seifert, A.C.; Rad, H.S.; Bhagat, Y.A.; Rajapakse, C.S.; Sun, W.; Lam, S.C.B.; Wehrli, F.W. Cortical Bone Water Concentration: Dependence of MR Imaging Measures on Age and Pore Volume Fraction. Radiology 2014, 272, 796-806. [CrossRef] [PubMed]

180. Yon, M.; Sarou-Kanian, V.; Scheler, U.; Bouler, J.-M.; Bujoli, B.; Massiot, D.; Fayon, F. Solid-State ${ }^{31} \mathrm{P}$ and ${ }^{1} \mathrm{H}$ Chemical MR Micro-Imaging of Hard Tissues and Biomaterials with Magic Angle Spinning at Very High Magnetic Field. Sci. Rep. $2017,7,8224$. [CrossRef] 